\title{
Regulation of MiR-124, Let-7d, and MiR-I8Ia in the Accumbens Affects the Expression, Extinction, and Reinstatement of Cocaine-Induced Conditioned Place Preference
}

\author{
Vijay Chandrasekar' and Jean-Luc Dreyer*,' \\ 'Division of Biochemistry, Department of Medicine, University of Fribourg, Fribourg, Switzerland
}

\begin{abstract}
Molecular adaptations underlying drug seeking and relapse remain largely unknown. Studies highlight post-transcriptional modifications mediated by microRNAs (miRNAs) in addiction and other neurological disorders. We have previously shown that chronic cocaine suppresses miR- 124 and let-7d and induces the expression of miR-I8I a in mesolimbic pathway. To further address the role and target gene regulation network of these miRNAs in vivo in cocaine addiction, we developed lentiviral vector (LV)-expressing miRNAs and their corresponding silencers for stable and regulatable miRNA expression. We tested in vivo miRNA gain and loss of function on cocaineinduced conditioned place preference (CPP) by localized LV-miRNA regulation in the nucleus accumbens (NAc). LV-miR-I24 and let-7d expression in the NAc attenuates cocaine CPP, whereas LV-miR-18Ia enhances it. Silencing miRNAs by corresponding LV-miRNA silencers expressing perfect miRNA target sequences inversed this effect on cocaine CPP. Doxycycline treatment for switching off silencer expression abolished the observed behavioral changes. Behavioral changes mediated by LV-miRNA regulation resulted in dynamic alterations in transcription factors, receptors, and other effector genes involved in cocaine-induced plasticity. Our results describe a complex regulatory pathway mediated by miRNAs in cocaine-mediated neuronal adaptations.

Neuropsychopharmacology (20 I I) 36, I I49-I I 64; doi: I0.1038/npp.20 10.250; published online 9 February 20 I I
\end{abstract}

Keywords: miRNA; cocaine; addiction; plasticity; lentivirus

\section{INTRODUCTION}

Drugs of abuse induce persistent structural and functional changes in the mesolimbic dopaminergic system, progressing towards the high-risk drug-seeking behavior and relapse. Emerging evidence suggests that drug-induced neuroplasticity depends on changes in gene expression and post-transcriptional regulation (McClung and Nestler, 2008; Nestler, 2008; Pietrzykowski et al, 2008; Huang and Li, 2008). Post-transcriptional regulatory processes play essential roles in neuronal plasticity, allowing rapid fine-tuning of protein composition in neurons in response to different stimuli (Blencowe, 2006; Grabowski and Black, 2001) and contribute to addiction (Pietrzykowski et al, 2008). Maladaptive memories that associate contextual/environmental stimuli with drugs provoke drug-craving and -seeking

\footnotetext{
*Correspondence: Professor J-L Dreyer, Division of Biochemistry, Department of Medicine, University of Fribourg, Chemin du Musée 5, Fribourg CH-1700, Switzerland, Tel: +4I 1263008632 , Fax: + 4l 026300 9735, E-mail: jean-luc.dreyer@unifr.ch Received 27 August 2010; revised 10 December 2010; accepted 15 December 2010
}

behavior during withdrawal (Lee et al, 2006; Rogers and See, 2007). Such memories following their retrieval may undergo a protein synthesis-dependent reconsolidation to be restored faithfully (Lee et al, 2005; Hellemans et al, 2006; Artinian et al, 2007; Bernardi et al, 2007), suggesting the crucial role of regulation of protein synthesis control in drug-associated memory processes.

MicroRNAs (miRNAs) are a class of small (19-25 nt) noncoding RNAs and are potent post-transcriptional regulators of gene expression (Ambros, 2004; Bartel, 2004; Filipowicz et al, 2008). Targeted mRNAs are selectively and reversibly suppressed translationally or subjected to degradation by miRNAs, possibly in a combinatorial manner based on the complementarity in the $3^{\prime}$-untranslated region ( $3^{\prime}$-UTR) of the mRNAs (Farh et al, 2005; Bhattacharyya et al, 2006; Kosik, 2006). Local translational control in spines is a powerful mechanism to regulate morphological and functional plasticity (Ashraf et al, 2006; Schratt, 2009), and recent studies show involvement of miRNAs in dendritic spine morphogenesis and development (Schratt et al, 2006; Siegel et al, 2009) and addiction (Pietrzykowski et al, 2008; Huang and $\mathrm{Li}, 2008$ ), especially to cocaine (Chandrasekar and Dreyer, 2009; Hollander et al, 2010; Schaefer et al, 2010; Im 
et al, 2010). The ability of miRNAs to form autoregulatory loops (Rybak et al, 2008; Johnston and Hobert, 2003) suggests their involvement in homeostatic or switch-like events during various phases of synaptic plasticity, as miRNAs can attract a variety of activities to their targets-even stimulating translation (Vasudevan et al, 2007). The complex outcome for the mRNAs upon targeted by miRNAs indicates that miRNAs serve as potent spatiotemporal regulators of the complex learning-related synaptic plasticity (Rajasethupathy et al, 2009), fine-tuning the levels of hundreds of proteins simultaneously and in a bidirectional manner (Schratt, 2009). Previously, we showed that miR-124 and let-7d are suppressed, whereas miR-181a is induced after chronic cocaine treatment (Chandrasekar and Dreyer, 2009). We have shown using in vitro studies a significant decrease in both mRNA and protein levels of brain-derived neurotrophic factor (BDNF) and dopamine D3 receptor (Drd3) by lentiviral vector (LV)-miR-124 and LV-let-7d, respectively, and suggested a feedback loop involving miR-124, let-7d, and miR181a along with cocaine-responsive transcription factors, neurotransmitter receptors, and other plasticity genes (Chandrasekar and Dreyer, 2009).

Here we investigate the effects of these miRNA in vivo in cocaine-induced conditioned place preference (CPP). LV-mediated expression of miR-124 and let-7d locally in the nucleus accumbens (NAc) attenuates cocaine CPP, whereas LV-miR-181a expression leads to an enhanced CPP effect. Conversely, silencing the respective miRNAs by using LVmediated silencer expression for the corresponding miRNAs resulted in an inverse behavioral effect on CPP. These behavioral effects were manifested by direct, primary, and secondary target gene expression changes at both transcript and protein levels mediated by corresponding LV-miRNAs. Identification of such drug-induced alterations in gene regulation is important for understanding molecular adaptations underlying addiction. These results show the dynamic miRNA gene regulation in cocaineinduced plasticity.

\section{METHODS}

\section{Lentiviral Expression Constructs and Viral Production}

LV miRNA expression constructs (LV-miR-124, LV-miR181a, LV-let-7d): LV expression constructs of individual miRNAs were generated by cloning a $\sim 450$-bp fragment containing either the rat miR-124, miR-181a, or let-7d precursor hairpin loops into the LV vector (Chandrasekar and Dreyer, 2009). Fragments obtained by PCR-based sense-antisense strand construction flanked by BamHI and $X h o I$ sites in the $5^{\prime}$ and $3^{\prime}$ ends, respectively, were cloned into pDrive cloning vector (Qiagen, Basel, Switzerland). Sequence-confirmed clones were subcloned into the pTK-431 lentiviral vector (LV) using BamHI/XhoI sites. The resultant lentiviruses are non-regulatable and express individual miRNAs under RNA Pol III mouse U6 promoter (Chandrasekar and Dreyer, 2009).

LV-miRNA-Silencer (miRNA-Sil) constructs (LV-miR124-Sil, LV-miR-181a-Sil, LV-let-7d-Sil): multiple perfect miRNA recognition elements (pMREs) of either miRNA-124, miR-181a, or let-7d were cloned separately in the form of tandem repeats consisting of four perfect complementary sequences into the $3^{\prime}$ region of the enhanced green fluorescent protein (EGFP) sequence present in the pTK433-EGFP LV-vector (Chandrasekar and Dreyer, 2009) (Supplementary Figure S1A). Sense oligos of $\sim 125 \mathrm{bp}$ with the four pMREs, corresponding to each miRNAs, were amplified by specific primers and were ligated into the pDrive cloning vector (Qiagen). Sequence-confirmed clones were subcloned into the pTK-433 LV-vector using the BamHI/XhoI sites. The specific LV-EGFP-pMREs miRNASil corresponding to each of the three miRNAs express the transcripts under the control of a doxycycline-regulatable CMV promoter, enabling stable expression of the miRNASil under the doxycycline-regulatable Tet-off system (Chandrasekar and Dreyer, 2009).

Lentivirus production: the LV-vector expression plasmids (either for miRNA pTK431-miR-124, pTK431-let-7d, or pTK431-miR-181a; or the three corresponding specific miRNA-Sil constructs pTK433-EGFP-pMREs-miR-Sil or the Doxycycline-regulatable control vector pTK433-EGFP, which expresses EGFP under the doxycycline-regulatable Tet-off system) were co-transfected into HEK293T cells along with the packaging construct plasmid $\mathrm{p} \Delta \mathrm{NRF}$ and the envelope plasmid PMDG-VSV-G to produce the viral particles (Boyer and Dreyer, 2007; Chandrasekar and Dreyer, 2009, 2010a, b). The viral titers were determined by 24 antigen measurements (KPL, Gaithersburgh, MD, USA). For in vivo experiments, the different viral stocks were matched for viral particle content and used at $0.2 \mathrm{mg} / \mathrm{ml}$ of p24. The efficiency of LV-miRNA viruses and their corresponding LV-miRNASil viruses were confirmed as shown previously by in vitro assays by using single/co-infection of the corresponding viruses into neuronal (NG-108-15) and non-neuronal cell lines (HEK293T) (Chandrasekar and Dreyer, 2009).

\section{Animal Handling}

All animal experiments were carried out in accordance with guidelines and regulations for Animal Experimentation, BAG, Bern, Switzerland. Male Wistar rats weighing 250-300 g (Janvier, FR) were used for all the experiments. The animals were housed in groups (four per cage) in clear plastic cages with wire grid lids. The animals were kept on a 12-h light/dark cycle (lights off at 0700 hours), with access to food and water ad libitum.

\section{Stereotaxic Surgery}

Stereotaxic surgery and LV injection were performed according to previous publications (Bahi et al, 2008a, b; Chandrasekar and Dreyer, 2010a,b). Rats were anesthetized with ketamine-xylazine (10 and $0.1 \mathrm{mg} / \mathrm{kg}$ ) (Streuli \& Co AG) administered i.p. Animals were injected into the NAc with $2 \mu \mathrm{l}$ of concentrated LV stock $(0.2 \mathrm{mg} / \mathrm{ml}$ of $\mathrm{p} 24$, corresponding to $8 \times 10^{9} \mathrm{IU} / \mathrm{ml}$ ). The injections were performed bilaterally at the following coordinates, as calculated from bregma and the dura mater: anterior +1.4 ; lateral \pm 1.2 ; and ventral-6.8 (Paxinos and Watson, 1998).

Animal groups and treatment. Ten groups of rats $(n=12)$ were used for the study. The first three groups were 
stereotaxically injected bilaterally in the NAc with either LV-miR-124 or LV-miR-181a or LV-let-7d. The second three groups of rats were injected in the NAc with the LV-miRNA-Sil, either LV-miR-124-Sil or LV-miR-181a-Sil or LV-let-7d-Sil. This group of animals was fed water supplemented with $5 \%$ sucrose throughout the experiment period for localized expression of the respective miRNA silencers. The third three groups of rats were also injected bilaterally in the NAc with the LV-miRNA-Sil, but were fed with water supplemented with 5\% sucrose and $0.02 \%$ doxycycline throughout the experiment period for complete inhibition of the respective LV-miRNA-Sil expression. The last group $(n=12)$ was injected with the control LV-GFP. Each group was further subdivided into two subgroups $(n=6)$ based on pairing treatment, in which the control saline-paired subgroup $(n=6)$ received only $0.9 \%$ saline ( $1 \mathrm{ml} / \mathrm{kg}$ i.p.) injections throughout the experiment and the cocaine-paired subgroup $(n=6)$ received saline/cocaine (20 mg/kg i.p.) on alternate days during the CPP conditioning period.

\section{Conditioned Place Preference}

CPP tests were performed during the dark cycle as described previously (Mueller and Stewart, 2000; Itzhak and Martin, 2002; Bahi et al, 2008a,b). During the preconditioning period, rats had free access in the chambers for $20 \mathrm{~min}$ daily CPP sessions for 3 days to habituate. On day 3, the CPP sessions were monitored using the Activity Monitor 5 software (MED Associates, USA). The time spent in each compartment was measured for $20 \mathrm{~min}$ as the pretest for the unconditioned preferences for all the animals. For cocaine-CPP training, rats injected with cocaine were immediately confined in their non-preferred compartment for $20 \mathrm{~min}$. During the conditioning phase (days 4-9), saline-paired rats received saline injections in both the compartments of the chamber, whereas cocaine-paired rats received saline in one compartment (days 4, 6, and 8) and cocaine $(20 \mathrm{mg} / \mathrm{kg}$ i.p.) in the other (days 5,7 , and 9). During the conditioning phase, a guillotine door blocked chambers and rats were confined to the appropriate compartment for $20 \mathrm{~min}$ daily sessions. On day 10, the post-conditioning CPP expression test was performed without any drug treatment and with free access to both compartments. The amount of time the rat spent in each chamber was monitored for $20 \mathrm{~min}$. Drug-induced place preference was expressed in seconds by post $v s$ pre, where post- and pre-values were the difference in time spent at the cocaine-paired site during post- and pre-conditioning periods, respectively (Bahi et al, 2008a, b).

\section{Extinction}

Immediately after the post-conditioning CPP test, rats $(n=12)$ were subjected to extinction of cocaine conditioning by undergoing $20 \mathrm{~min}$ daily sessions without any injections and complete access to both the compartments of the CPP chambers. Complete extinction of CPP in cocaine-conditioned animals was attained in 12 days and is defined as the return to exploratory times that did not differ significantly from the saline-paired control animals (Bahi et al, 2008a, b).
Reinstatement of CPP by Low Doses of Cocaine Priming after Extinction

After the complete extinction was established, animals were subjected to reinstatement of CPP. The day after the last extinction session, all groups ( $n=12 /$ group) received a priming injection of $0.9 \%$ saline $(1 \mathrm{ml} / \mathrm{kg}$ i.p.) and free access to both compartments $(20 \mathrm{~min})$ to monitor the amount of time the rat spent in each chamber. This was followed $24 \mathrm{~h}$ later with a priming injection of low-dose cocaine $(2 \mathrm{mg} / \mathrm{kg}$ i.p.) with a $20 \mathrm{~min}$ session to monitor the reinstatement of the CPP in the different groups (Bahi et al, 2008a, b).

All animals were killed by decapitation $24 \mathrm{~h}$ after the last injection and brains were removed and stored rapidly, either in TRIzol reagent (Invitrogen, Basel, Switzerland) for RNA extraction or cryo-preserved in isopentene for immunohistochemistry and in situ hybridization.

\section{Total RNA Isolation}

HEK-293T cells or rat brain parts (microdissected) were homogenized in TRIzol reagent (Invitrogen). Total RNA was extracted according to the manufacturer's instructions. For the purpose of RNA isolation, brains from four animals per each group $(n=12)$, that is, two animals per each subgroup (saline/cocaine) ( $n=6 /$ subgroup) from the respective different lentiviral-treated and naive un-operated animal groups were used. RNA was quantified by spectrometry, and its integrity was verified by $2 \%$ agarose gel electrophoresis and visualized with ethidium bromide staining. RNA samples were stored at $-70{ }^{\circ} \mathrm{C}$.

Quantification of mature miRNA by real-time $q R T-P C R$. Expression profiling of mature miRNA was performed after reverse transcriptase using specific RT primers (Taqman MicroRNA Assay, Applied Biosystem, Cheshire, UK) using the manufacturer's guidelines. For RT $10 \mathrm{ng}$ of total RNA from microdissected tissue was used per cDNA preparation. cDNA was used at a dilution of $1: 15$ in qRT-PCR. Twenty microliters of total reaction mixture included rat miRNAspecific probes, primer sets, and the Taqman Universal PCR Master Mix. Reactions were performed on an iCycler (BioRad, Reinach, Switzerland). Cycling parameters were $95^{\circ} \mathrm{C}$ for $10 \mathrm{~min}$, followed by 45 cycles of $95^{\circ} \mathrm{C}(15 \mathrm{~s})$ and $60^{\circ} \mathrm{C}(1 \mathrm{~min})$. All reactions were performed in quadruplicates and the relative abundance of each target was calculated with U6 snRNA normalization and the median Ct (cycle threshold) value was used for the analysis (Chandrasekar and Dreyer, 2009) To determine the linearity and detection limit of the assay, cDNA samples were amplified for successive 10 -fold dilutions in a series of realtime PCRs, using a duplicate assay on each dilution, so that the correlation coefficient could be calculated from the standard curve of $\mathrm{Ct}$ values. The $\Delta \mathrm{Ct}$ for each candidate was calculated as: $\Delta \mathrm{Ct}=(\mathrm{Ct}$ (candidate) $-\mathrm{Ct}(\mathrm{U} 6 \mathrm{snRNA}))$. The relative abundance of each target can be calculated as the ratio between treated and untreated samples (Chandrasekar and Dreyer, 2009). Comparisons were made between cocaine and saline groups, and the significance was calculated using two-way analysis of variance (ANOVA), followed by Bonferroni post hoc tests and the level of 
statistical significance was set at $P<0.05$. Data were expressed as means \pm SEM.

\section{RT-PCR Quantification of the Effect of LV-miRNA Overexpression on Specific Target Genes}

The effects of overexpression or silencing of miRNAs miR124 , let-7d, and miR-181a on their respective target genes at the mRNA levels were tested by qRT-PCR. RNA from NAc region microdissected after the in vivo expression and behavioral experiments were reverse transcribed. The cDNAs were prepared using $4 \mu \mathrm{g}$ of RNA from each sample reverse transcribed at $42{ }^{\circ} \mathrm{C}$ for $30 \mathrm{~min}$ with $1 \mu \mathrm{g}$ of Oligo $(\mathrm{dT})$ or random hexamers, $5 \times$ first-strand buffer, $100 \mathrm{mM}$ DTT, $10 \mathrm{mM}$ dNTP, Rnasin (Invitrogen), and M-MLV reverse transcriptase (Promega, Wallisellen, Switzerland). Primer sets were designed to amplify $100-200$ bp products, using the PRIMER3 software: (http://frodo.wi.mit.edu/ cgi- bin/primer3/primer3_www.cgi). PCR reaction mixtures included cDNAs in optimum dilution, the SYBR-Green qPCR Master mix (BioRad, Reinach, Switzerland), and $10 \mu \mathrm{M}$ primers, in a total reaction volume of $20 \mu \mathrm{l}$. Expression profiling was carried out with dissociation curves using iCycler (BioRad). Cycling parameters were $95^{\circ} \mathrm{C}$ for $4 \mathrm{~min}$, followed by 40 cycles of $2^{\circ} \mathrm{C} / \mathrm{s}$ temperature transition rate up to $95^{\circ} \mathrm{C}(30 \mathrm{~s})$ and $62^{\circ} \mathrm{C}(45 \mathrm{~s})$, followed by melting curve analysis. All reactions were performed in triplicates with reference dye normalization (cyclophilin) and the median $\mathrm{Ct}$ (cycle threshold) value was used for the analysis. To determine the linearity and detection limit of the assay, cDNA samples were amplified for successive 10-fold dilutions in a series of real-time PCRs, using a duplicate assay on each dilution, so that the correlation coefficient could be calculated from the standard curve of $\mathrm{Ct}$ values. The $\Delta \mathrm{Ct}$ for each candidate was calculated as: $\Delta \mathrm{Ct}=(\mathrm{Ct}$ (candidate)-Ct (cyclophilin)). The relative abundance of each target can be calculated as the ratio between treated and untreated samples (Boyer and Dreyer, 2007; Chandrasekar and Dreyer, 2009, 2010b). The PCR reaction was evaluated by melting curve analysis and by checking the PCR products on $2 \%$ agarose gel. Comparisons were made between different groups and subgroups (cocaine and saline groups), and significance was calculated using two-way ANOVA, followed by Bonferroni post hoc tests and the level of statistical significance was set at $P<0.001$. Data were expressed as means \pm SEM. The following primers sets were used for amplification: cyclophilin - forward, 5'-GTGAGAA GGGCTTTGGCTAC- $3^{\prime}$ and reverse, $5^{\prime}$-TTCTCGTCAGGAA AGCGG-3'; $\beta$-actin - forward, $5^{\prime}$-AGCCATGTACGTAGCCA TCC- $3^{\prime}$ and reverse, $5^{\prime}$-CTCTCAGCTGTGGTGGTGAA- $3^{\prime}$; NZF-2b/7ZFMyt1 - forward, 5'-GCAGACCTCAGTTGTCCT ACC- $3^{\prime}$ and reverse, 5'-CTTGGATACCAGGTGCTCAG-3'; BDNF-forward, $5^{\prime}$-GGTTCGAGAGGTCTGACGAC- $3^{\prime}$ and reverse, $5^{\prime}$-CAAAGGCACTTGACTGCTGA-3'; TrkB - forward, $5^{\prime}$-CCTCGTCGGAGAAGATCAAG- $3^{\prime}$ and reverse, 5'-CGTGGTACTCCGTGTGATGT-3'; REST1 - forward, 5'-C GAGTTGATGCCTGTTGGAGAC- $3^{\prime}$ and reverse, $5^{\prime}$-TGC TTCAAATACGGGCTGGG-3'; nucleus accumbens-associated protein-1 (NAC1) - forward, 5'-GCTCTTCCTGAGC AGGTCGT- $3^{\prime}$ and reverse, $5^{\prime}$-GTGCCTGTCACAAGCTCC AG-3'; urokinase plasminogen activator (uPA) - forward, $5^{\prime}$-CAGATCCGATGCTCTTAGCC-3' ${ }^{\prime}$ and reverse, 5'-TAGA
GCCTTCTGGCCACACT-3'; dopamine transporter (DAT) forward, $5^{\prime}$-GTTCTACGGCGTCCAGCA-3' and reverse, $5^{\prime}$-TGACCACGACCACATACAGG-3'; mammalian period homologue-2 (mPer2) - forward, 5'-GCTTCACCATGCCTG TTGT- $3^{\prime}$ and reverse, $5^{\prime}$-GGAGTTATTTCGGAGGCAAGT GT-3'; dopamine D2 receptor (Drd2) - forward, 5'-CAT TGTCTGGGTCCTGTTCCT- $3^{\prime}$ and reverse, $5^{\prime}$-GACCAGCAG AGTGACGATGA-3'; Drd3 - forward, 5'-GGGGTGACTGTC CTGGTCTA- $3^{\prime}$ and reverse, $5^{\prime}$-TGGCCCTTATTGAAAACT GC-3'; FosB - forward, 5'-GTGAGAGATTTGCCAGGGTC-3' and reverse, $5^{\prime}$-AGAGAGAAGCCGTCAGGTTG-3'; truncated splice variant of FosB ( $\Delta$ fos) - forward, $5^{\prime}$-AGGCAGAG CTGGAGTCGGAGAT- $3^{\prime}$ and reverse, $5^{\prime}$-GCCGAGGACTTG AACTTCACTCG-3'; methyl-CpG binding protein-2 (MeCP2) - forward, 5'-AAGTCTGGTCGCTCTGCTG- ${ }^{\prime}$ and reverse, 5'-GTTAGGTGGTTTCTGTTCTCTGG-3'; $i$-opioid receptor-1 (MOR1) - forward, 5'-CATCAAAGCACTGATCA CGATTCC- $3^{\prime}$ and reverse, 5'-TAGGGCAATGGAGCAGTT TCTGC- $3^{\prime}$; integrin- $\beta 1$ (ITG $\beta 1$ ) - forward, $5^{\prime}$-TTGATTCTTAAGTCAGCAGTGG- $3^{\prime}$ and reverse, $5^{\prime}$-CTTTCGTCCATTT TCTCCTGTC-3'; metabotropic glutamate receptor-5 (GRM5) - forward, 5'-CCACTGACGACTTGACAGGTT-3' and reverse, 5'-CAGTAACGAAGAGGGTGGCTA-3'; ionotropic glutamate AMPA-receptor-2 (GRIA2) - forward, $5^{\prime}$-CTGAGTGCCTTACACAATGGTTTC- $3^{\prime}$ and reverse, $5^{\prime}$-C GGATGCCTCTCACCACT-3'; polypyrimidine tract binding protein-1 (Ptbp1) - forward, 5'-AGTGCGCATTACACTG TCCA- $3^{\prime}$ and reverse, 5'-CTTGAGGTCGTCCTCTGACA-3'; neural polypyrimidine tract binding protein ( $\mathrm{Ptbp} 2)$ - forward, 5'-GCAGAAGAGGATCTGCGAAC- $3^{\prime}$ and reverse, $5^{\prime}$-CATCTTCATCTCCCGTGCTT- $3^{\prime}$; and for the sensor EGFP - $5^{\prime}$-ATGGTGAGCAAGGGCGAG- ${ }^{\prime}$ and $5^{\prime}$-GTGGTG CAGATGAACTTCA-3'.

\section{Western Blotting}

Transfected cells (HEK293T or NG 108-15) or rat brain NAc region (microdissected) were homogenized in the buffer (50 mM Tris, pH 7.5; $120 \mathrm{mM} \mathrm{NaCl}, 1.5 \mathrm{mM} \mathrm{CaCl}_{2}, 5 \mathrm{mM}$ $\mathrm{MgCl}_{2}, 5 \mathrm{mM} \mathrm{KCl}, 5 \mathrm{mM}$ EDTA) with a protease inhibitor mixture $(1 \mathrm{ml} / 20 \mathrm{~g}$ of tissue; Sigma). For the purpose of protein extraction, brain tissues from six animals per each group $(n=12)$, that is, three animals per each subgroups (saline/cocaine) ( $n=6 /$ subgroup) from the respective different lentiviral-treated and naive un-operated animal groups were used. Homogenates were solubilized with $1 \%$ digitonin, followed by the addition of secondary solubilization buffer $(50 \mathrm{mM}$ Tris, pH 7.6, $150 \mathrm{mM} \mathrm{NaCl}, 1 \%$ Nonidet-P40, $0.5 \%$ sodium deoxycholate, $2 \mathrm{mM}$ EDTA, $1 \mathrm{mM}$ Na-vanadate, $1 \mathrm{mM}$ phenylmethylsulfonyl fluoride, $1 \%$ Triton X-100), and centrifuged at $10000 \mathrm{~g}$ at $4{ }^{\circ} \mathrm{C}$ for $15 \mathrm{~min}$. Solubilized extracts were subjected to sodium dodecylsulfate-polyacrylamide gel electrophoresis. Blots were blocked with $5 \%$ non-fat dried milk dissolved in TBST (10 mM Tris, $150 \mathrm{mM} \mathrm{NaCl}, 0.1 \%$ Tween-20) for $1 \mathrm{~h}$ at room temperature and incubated overnight at $4{ }^{\circ} \mathrm{C}$ with primary antibodies for either BDNF (either 1:300; sc-20981 (H-117), Santa Cruz Biotechnology, Santa Cruz, CA, USA; or 1:500; ab6201, Abcam, Cambridge, UK) or GFP (1:1000; G-6539, Sigma) or Drd3 (1:1000; BP4275, Acris) or cAMP-responsive element binding protein (CREB) (phospho S133; $1: 500$; ab32096, Abcam) or FosB $(1: 335$; ab11959, Abcam) or uPA 
(1:500; ab24121, Abcam) or MOR1 (1:1000; ab10275, Abcam) or DAT ( $1: 1000$; ab5990, Abcam) or mPer2 (1:1000; PER21-S, Alpha Diagnostic) or EPH-B1 receptor tyrosine kinase (EphB1) (1:300; sc-9319(M-19, Santa Cruz Biotechnology). Blots were washed three times with TBST and incubated for $1 \mathrm{~h}$ with the peroxidase-conjugated secondary antibody solution. Proteins were then visualized using enhanced chemiluminescence (Millipore, Zurich, Switzerland). Membranes were washed for $30 \mathrm{~min}$ in TBST and placed in stripping solution $(25 \mathrm{mM}$ glycine- $\mathrm{HCl}, \mathrm{pH} 2.0,1 \%$ sodium dodecylsulfate) for $30 \mathrm{~min}$ and used as described above for $\beta$ actin detection (1:4000; ab1801, Abcam). Protein band signals were estimated using the Quantity one (Bio Rad, Hempstead, UK) software and normalized against $\beta$-actin signal (Chandrasekar and Dreyer, 2009, 2010b; Boyer and Dreyer, 2007).

\section{Statistical Analysis}

Data in graphs are presented as mean \pm SE. The primary dependent variable was time spent in cocaine-paired compartment. The significance of differences between groups was determined by a two-way ANOVA, followed by Bonferroni's post hoc tests. Extinction phase of CPP data was analyzed using repeated measures ANOVA for the 12 days of extinction, with test as within-subject variable and LV treatment as between-subject factor, followed by Bonferroni's post hoc tests. Main and interaction levels were considered significant at $P<0.05$. All the analysis was carried out using GraphPad PRISM (V4.0, GraphPad, San Diego, CA, USA).

\section{RESULTS}

\section{Lentiviral-Mediated Regulation of Mir-124, Mir-181a, and Let-7d Expression in the Nac Modulates CPP}

LVs expressing either miRNA or their specific silencers induce local expression/suppression in the NAc, enabling to determine the effects of overexpression or silencing of specific miRNA in cocaine-induced CPP. The three LV vectors expressing the individual miRNA were under non-regulatable promoters, whereas expressions of LVmiRNA-Sil were doxycycline regulatable. Each of the three individual LV-miRNA-Sil were injected into two separate groups $(n=12)$, wherein one group was fed without doxycycline throughout the experimental period to express the silencers and the other with doxycycline to prevent the expression of the miRNA-Sil (see Methods). The tenth group (control) was injected LV-GFP, enabling regulatable GFP expression. During the pre-conditioning period (days 1-3; Figure 1a), all 10 groups were tested for evidence of bias towards either compartment in the conditioning chamber; no evidence of significant bias was observed between the chambers during the day 3 of the preconditioning recordings. Animals were then conditioned for place preference and the CPP recordings were performed on day 10 (Figure 1a). All saline-paired groups displayed no significant difference compared with controls in the time spent in both compartments, whether fed with or without doxycycline. Previous studies from our lab have shown that the CPP displayed by the LV-GFP group remain unchanged, irrespective of whether they were fed doxycycline or not
(Bahi et al, 2008a,b). In addition, naive un-operated animals exhibited CPP score indistinguishable from that observed with the LV-GFP group (Figure 1), highlighting the suitability of LV-GFP as the control. The results of the CPP experiment were expressed by post-pre values, where the values are the difference in time spent at the drugpaired chamber during post- and pre-conditioning periods (see Methods).

Mir-124. Expression of miR-124 in the NAc by LV-miR-124 resulted in $\sim 50 \%$ decrease in the CPP score compared with the LV-GFP control group (Figure $1 \mathrm{~b} ; \mathrm{F}_{4,50}=9.43$, $P<0.0001)$. In contrast, when miR-124 is silenced locally in the NAc, the LV-miR-124-Sil group fed without doxycycline-enabling the expression of the silencer displayed a $\sim 50 \%$ increase in CPP compared with the LV-GFP group. Furthermore, when fed doxycycline (to inhibit the Silencer expression), the similar LV-miR-124-Sil group showed no change in cocaine CPP and was comparable to the control GFP group. The CPP score observed after differential regulation of miR-124 in the NAc of different groups was specific to cocaine-pairing treatment $\left(F_{1,50}=329.26\right.$, $P<0.0001$ ), and no significant difference was observed in saline-paired groups. These data suggest the specificity of the miRNA silencing and show that miR-124 overexpression in the NAc during the acquisition phase of cocaine-induced $\mathrm{CPP}$ results in a decreased preference for the cocaine-paired chamber.

Mir-181a. Expression of miR-181a in the NAc by LV-miR181 a resulted in $\sim 30 \%$ increase in the CPP score compared with the LV-GFP group (Figure $1 c ; \mathrm{F}_{4,50}=3.47, P=0.0140$ ). By contrast, the LV-miR-181a-Sil group (fed without doxycycline) displayed a $>55 \%$ decrease in CPP, whereas a similar LV-miR-181a-Sil group fed doxycycline showed no change in cocaine-induced CPP compared with the LV-GFP group. The CPP score observed was specific to cocainepairing treatment $\left(\mathrm{F}_{1,50}=250.54, P<0.0001\right)$, and no significant difference was observed in saline-paired groups.

Let-7d. Expression of let-7d in the NAc by LV-miR-let-7d resulted in $>50 \%$ decrease in the CPP score compared with the LV-GFP group (Figure 1d; $F_{4,50}=24.11, P<0.0001$ ). Silencing of let-7d in LV-let-7d-Sil group (fed without doxycycline) resulted in a significantly increased preference ( $>55 \%$ increase) for the cocaine-paired chamber compared with the LV-GFP group. The LV-let-7d-Sil group fed with doxycycline showed no change in cocaine-induced CPP compared with the LV-GFP group. The CPP score observed was specific to cocaine pairing $\left(F_{1,50}=293.73, P<0.0001\right)$, and no significant difference was observed in saline-paired groups.

\section{miRNA Regulation in Nac Affects Extinction of Cocaine CPP}

After CPP monitoring on day 10, animals were placed daily into the setup for $20 \mathrm{~min} /$ day for 12 days - but without injections during the extinction period with access to both chambers. Animals conditioned with saline pairing displayed no significant behavioral changes throughout the 


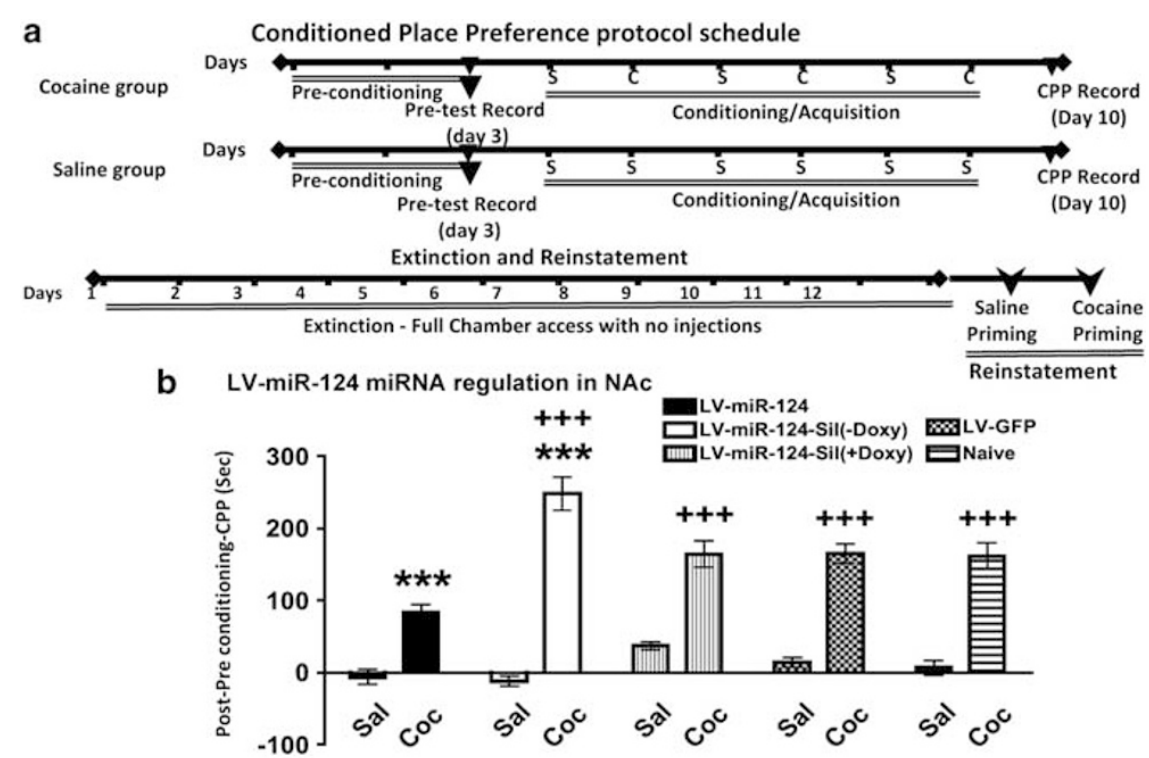

C LV-miR-181a miRNA regulation in NAC

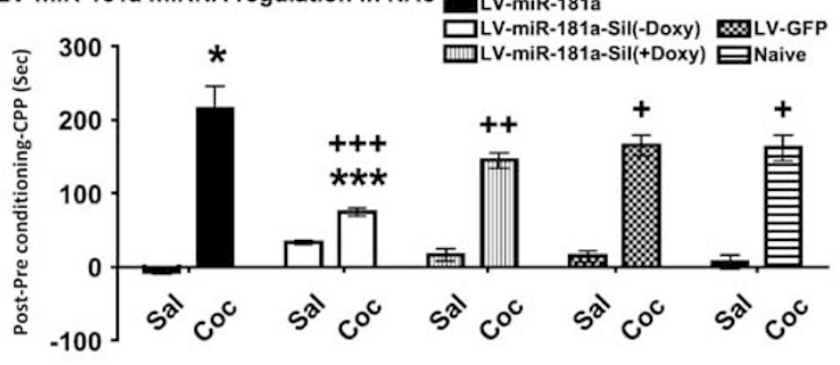

d LV-let-7d miRNA regulation in NAc

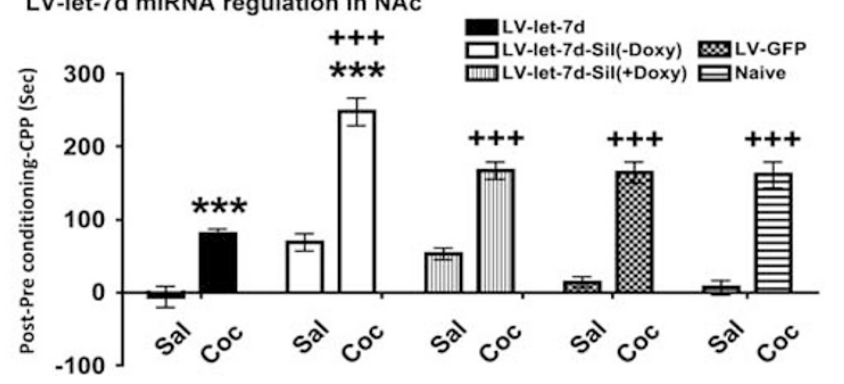

Figure I Localized microRNA (miRNA) regulation in the nucleus accumbens (NAc) affects cocaine-induced conditioned place preference (CPP). (a) Schematic representation of behavioral training and testing schedule used. Ten groups of animals $(n=12)$ were treated with lentiviruses expressing either green fluorescent protein (GFP) control or miRNAs (non-regulatable lentiviral vector (LV)-miR-124, miR-I8Ia, or let-7d) or miRNA-Silencers (Sil) (regulatable LV-miR-I24-Sil, miR-I8Ia-Sil, or let-7d-Sil, either with or without doxycycline), and subjected to cocaine-induced CPP. All groups ( $n=12$ ) were further subdivided into two sets cocaine $(n=6)$ and saline $(n=6)$ (control). After 3 days pre-conditioning recording, during the conditioning phase (days 4-9), animals received either saline or cocaine (20 mg/kg i.p.) in their corresponding cue-paired chamber (see Methods), followed by recording on day 10. After extinction over 12 days with no injection, saline priming was performed, followed by $24 \mathrm{~h}$ of cocaine priming and the reinstatement was recorded. (b) Expression of miR-124 in the NAc attenuates cocaine-induced CPP, whereas local knockdown of miR-124 promotes cocaine-induced CPP. (c) Conversely, miR- I8I a expression enhances cocaine-induced CPP, whereas local knockdown of miR-I 8 I a attenuates cocaine-induced CPP. (d) Similar to miR-124, expression of let-7d in the NAc attenuates cocaine-induced CPP, whereas local knockdown enhances cocaine-induced CPP. In all cases, doxycycline-mediated inhibition of corresponding miRNA-Sil expression brings the CPP score back to the control group levels. Data show the mean $( \pm \mathrm{SEM}) . * P<0.05, * * P<0.0 \mathrm{I}$, and ${ }^{*} * * P<0.00$ I represents values significantly different from cocaine-paired LV-GFP group; ${ }^{+} P<0.05,{ }^{+}+P<0.0 \mathrm{I}$, and ${ }_{+++} P<0.00$ I represents values significantly different from cocaine-paired corresponding LV-miRNA-expressing group; two-way analysis of variance (ANOVA), followed by Bonferroni post hoc tests.

extinction period (Supplementary Figure S2A; for miR-124 group: $\mathrm{F}_{5,120}=0.36, P=0.874$; for miR-181a group: $\mathrm{F}_{5,120}=$ $0.94, P=0.4548$; for let-7d group: $\mathrm{F}_{5,120}=1.10, P=0.3649$, compared with the LV-GFP group), irrespective of whether or not they had been fed doxycycline. In contrast, animals conditioned with cocaine pairing displayed extinction to
CPP in a progressive manner over the 12-day testing period (Figure 2a-c): within-subject analysis of LV-GFP animals showed no significant difference between day $6 v s$ day 7 , indicating the establishment of CPP extinction in this group; on the other hand, the LV-miR-124-treated group showed a much shorter extinction latency, which lasted only 
CPP extinction of Cocaine Groups

a miR-124

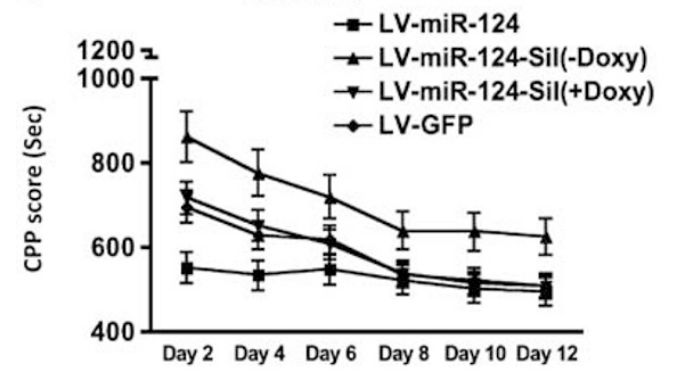

b

miR-181

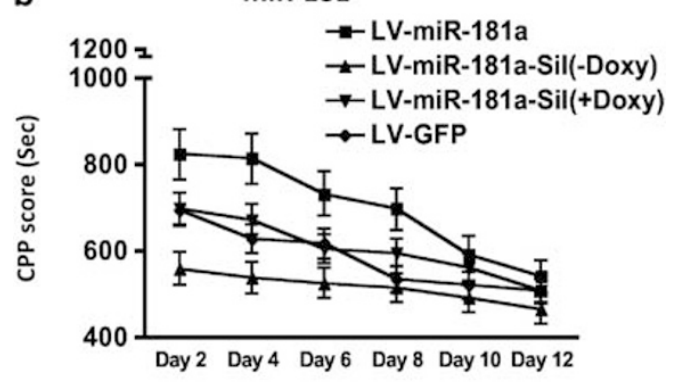

C

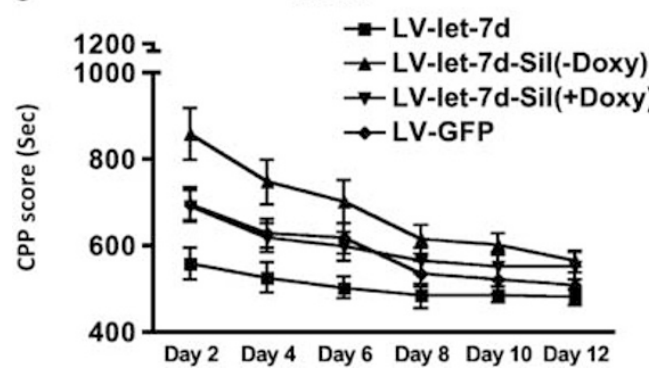

Figure 2 Regulation of microRNA (miRNA) expression in the nucleus accumbens (NAc) affects the rate of extinction in cocaine-induced conditioned place preference (CPP). Post-training extinction data of cocaine-paired animals from the different lentiviral vector (LV) groups are shown. Ten groups of animals ( $n=12 /$ group) were pre-tested, trained, and tested for CPP as displayed in Figure 1. After the CPP recording on the I0th day, rats were subjected over 12 days to CPP extinction in 20 min daily sessions with full chamber access but no injections (see Methods). LV-mediated miR-I24 (a), miR- I 8 I a (b), or let-7d (c) regulation in the NAc modulates the extinction rate of cocaine-induced CPP compared with the control LV-green fluorescent protein (GFP) levels, likely due to the high starting point in extinction. Values represent mean \pm SEM.

3-4 days (Figure 2a; $\mathrm{F}_{3,120}=24.17, P<0.0001$ ), whereas silencing miR-124 resulted in a longer extinction latency, which lasted for 9-10 days, but this effect could likely be due to the already high CPP observed in this group. Doxycycline-treated miR-124-Sil group remained comparable to the LV-GFP group and these effects were specific to cocaine conditioning $\left(\mathrm{F}_{5,120}=12.55, P<0.0001\right)$.

The group injected with LV-miR-181a showed a longer extinction latency, which lasted for 10-11 days, again likely due to pre-existing high CPP observed in this group (Figure 2b; $\mathrm{F}_{3,120}=23.64, P<0.0001$ ), whereas silencing miR-181a by LV-miR-181-Sil resulted in a much shorter extinction latency lasting only 5-6 days. When the silencer expression is suppressed by doxycycline treatment, the extinction latency was not significantly different from the control group, and these effects were specific to cocainepaired conditioning $\left(\mathrm{F}_{5,120}=14.05, P<0.0001\right)$.

Overexpression of let-7d resulted in a shorter extinction latency similar to LV-miR-124 group, and lasted only 5-6 days, (Figure 2c; $F_{3,120}=25.96, P<0.0001$ ). When let-7d miRNA was suppressed, the extinction latency increased up to 9-10 days; however, this increased extinction period was absent in the let-7d-Sil group treated with doxycycline, which displayed extinction latency comparable to the control group. These effects again were specific to the cocaine-paired animals $\left(\mathrm{F}_{5,120}=14.94, P<0.0001\right)$.

After the end of the extinction period (day 12) when no significant difference could be observed between the groups, saline/cocaine priming was performed to assess the reinstatement of $\mathrm{CPP}$.

\section{Effect of LV-miRNA Regulations on the Reinstating Properties of Cocaine}

After the 12 days of withdrawal and achieving extinction of CPP, all the animals received a single saline injection, followed $24 \mathrm{~h}$ later by either a single low-dose cocainepriming injection $(2 \mathrm{mg} / \mathrm{kg})$ to cocaine-paired groups or a single dose of saline to saline-paired groups and reinstatement of CPP was tested (see Methods). As shown in Supplementary Figure S2B, injection of saline had no effect on reinstatement of CPP in all animal group sets, irrespective of the groups or the doxycycline treatment between subject factor (miR-124: $\mathrm{F}_{1,40}=1.73, P=0.1959$; miR-181a: $\mathrm{F}_{1,40}=0.02, P=0.8806$; let-7d: $\mathrm{F}_{1,40}=0.0, P=$ 0.9496). Furthermore, saline injection to saline-paired animals also had no effect on the reinstatement of cocaine CPP in the different groups, regardless of the LV-mediated miRNA regulation (Figure 3; miR-124: $\mathrm{F}_{3,40}=0.18$, $P=0.9081$; miR-181a: $\mathrm{F}_{3,40}=0.97, P=0.4154$; let-7d: $\mathrm{F}_{3,40}=$ $2.41, P=0.0810)$.

However, when cocaine-paired animals were given a single injection of low-dose cocaine, drug-induced place preference was immediately reinstated (Figure $3 a-c)$. The control, naive un-operated, and LV-GFP groups displayed a modest preference for the cocaine-paired compartment by spending $\sim 53 \%$ of the time in that chamber, similar to the behavior observed before extinction. Animals injected with LV-miR-124 displayed a significantly lesser preference, spending $\sim 43 \%$ of the time in the cocaine-paired compartment (Figure 3a; $F_{3,40}=9.36, P<0.0001$ ), whereas silencing of miR-124 (in the LV-miR-124-Sil group fed without doxycycline) leads to a significant increase in the exploratory time $(\sim 60 \%)$ spent on the cocaine-paired compartment. In contrast, the magnitude of reinstatement was not observed in the LV-miR-124-Sil group fed with doxycycline, where animals displayed a reinstatement ( $\sim 54 \%)$ similar to LV-GFP group and was specific to cocaine priming $\left(\mathrm{F}_{1,40}=124.10, P<0.0001\right)$. By comparison saline-injected groups showed no changes in the CPP reinstatement. These results show that differential regulation of miR-124 in the NAc during acquisition significantly affect the cocaine-induced $\operatorname{CPP}\left(\mathrm{F}_{3,40}=3.04, P=0.0398\right)$.

Upon cocaine priming, cocaine-paired animals injected with LV-miR-181a displayed no significant difference in the time spent $(56.5 \%)$ on the cocaine-paired chamber compared with LV-GFP group, whereas silencing of miR-181a 
CPP reinstatement: Cocaine Priming$$
\text { a }
$$

a miR-124

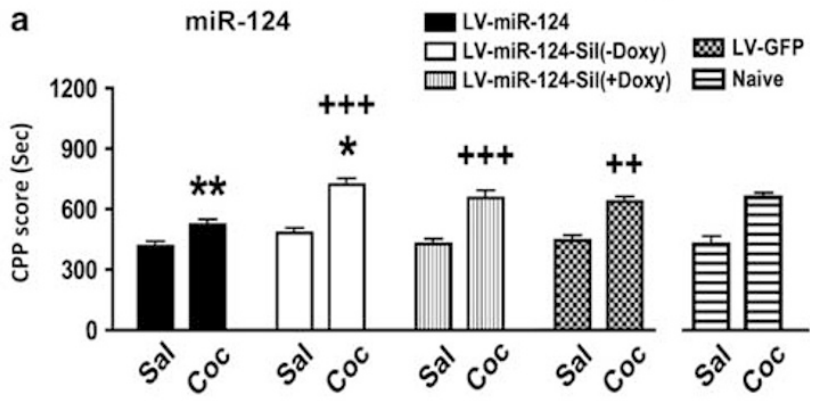

b miR-181a

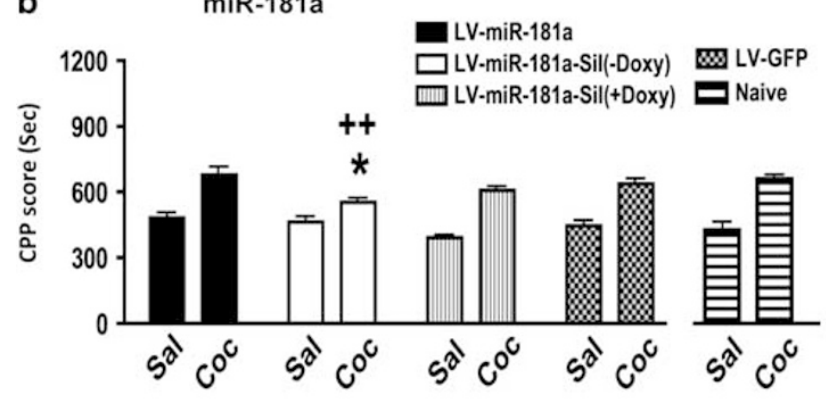

C
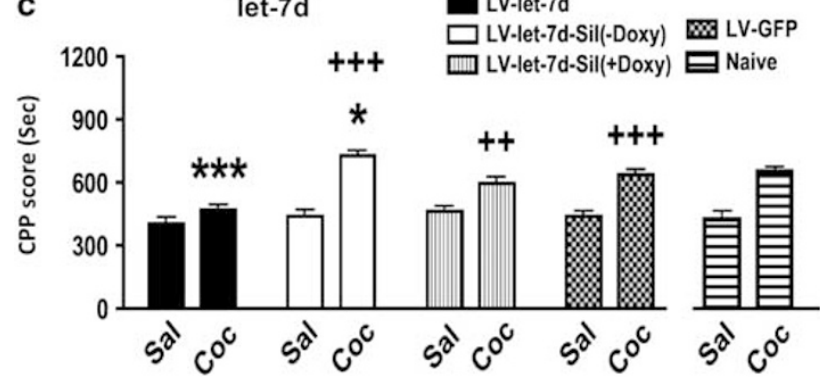

Figure 3 Effect of microRNA (miRNA) regulation in the nucleus accumbens (NAc) on cocaine reinstatment. After the cocaine-induced conditioned place preference (CPP) recording and establishment of extinction (by means of prolonged drug withdrawal over 12 days), animals were subjected to priming injections of $0.9 \%$ saline ( $\mathrm{ml} / \mathrm{kg}$ i.p.), followed $24 \mathrm{~h}$ later by a priming dose of either saline or cocaine $(2 \mathrm{mg} / \mathrm{kg}$ i.p.) and place preference was recorded for 20 min (see Methods). Lentiviral vector (LV)-miRNA regulation in the NAc affects reinstating properties of cocaine after single priming with low-dose cocaine $(2 \mathrm{mg} / \mathrm{kg})$. LV-miR-I24 (a) and LV-let-7d (c) expression results in an attenuated reinstatement of CPP, whereas silencing miR-124 and let-7d leads to an enhanced reinstatement of cocaine-induced CPP compared with the control LV-green fluorescent protein (GFP) group. Conversely, silencing of miR-I8la (b) shows an attenuated reinstatement for cocaine-induced CPP compared with the control LV-GFP group. Values represent mean \pm SEM. ${ }^{*} P<0.05$, *** $P<0.01$, and $* * * P<0.001$ represents values significantly different from LV-GFP group; ${ }^{+} P<0.05,{ }^{++} P<0.01$, and ${ }^{+}{ }^{+}+P<0.00$ I represents values significantly different from cocaine-paired corresponding LV-miRNA expressing group, by two-way analysis of variance (ANOVA), followed by Bonferroni post hoc tests.

(in the LV-miR-181a-Sil group fed without doxycycline) led to a significant decrease $(\sim 46 \%)$ in the time spent on the cocaine-paired compartment compared with the LV-GFP group (Figure $3 \mathrm{~b} ; \mathrm{F}_{3,40}=4.19, P=0.0114$ ). Upon cocaine priming, no difference was observed in the LV-miR181a-Sil group fed doxycycline, where the animals displayed a reinstatement $(50.5 \%)$ similar to $L V-G F P$ group; this was specific to cocaine priming $\left(\mathrm{F}_{1,40}=100.07, P<0.0001\right)$ as the saline-injected group showed no change in the reinstatement of CPP. These data show that differential regulation of miR-181a in the NAc, while significantly affecting expression of cocaine-induced CPP, had no significant effect on $\mathrm{CPP}$ reinstatement after extinction $\left(\mathrm{F}_{3,40}=2.61, P=0.0645\right)$.

On the contrary, cocaine priming of cocaine-paired animals injected with LV-let-7d displayed a significantly lesser preference than the LV-GFP, spending $\sim 39 \%$ of the time in the cocaine-paired compartment (Figure $3 \mathrm{c}$; $\left.\mathrm{F}_{3,40}=10.39, \quad P<0.0001\right)$, whereas silencing of let-7d (in the LV-let-7d-Sil group fed without doxycycline) led to a significant increase $(\sim 61 \%)$ in the exploratory time spent in this compartment. In contrast, the magnitude of reinstatement was not observed in the LV-let-7d-Sil group fed doxycycline, displaying a reinstatement $(\sim 50 \%)$ similar to LV-GFP group that was specific to cocaine priming $\left(\mathrm{F}_{1,40}=78.73, P<0.0001\right)$; by comparison, saline in the injected group showed no changes in the reinstatement of CPP. Taken together, this shows that differential regulation of let-7d in the NAc during acquisition significantly affects the cocaine-induced $\mathrm{CPP}\left(\mathrm{F}_{3,40}=6.20, P=0.0015\right)$.

\section{LV-mIR-124 Expression after Previous Cocaine Conditioning Fails to Attenuate the Reinstating Properties of Cocaine}

To check whether miRNA regulation by lentiviral injection in the NAc after the establishment of cocaine CPP has any effect on the reinstating properties of cocaine, three groups of rats were stereotaxically injected with LV-miR-124, or its silencer or LV-GFP after the previous cocaine CPP. A fourth naive un-operated group was used as the other control. The groups were subjected to extinction of CPP, after which all the animals received a single saline injection, followed $24 \mathrm{~h}$ later by either a single low-dose cocaine injection $(2 \mathrm{mg} / \mathrm{kg})$ to cocaine-paired groups or a single dose of saline to saline-paired groups and reinstatement of CPP was tested (see Supplementary Methods). As with previous experiments, injection of saline had no effect on reinstatement of CPP in all groups, irrespective of the LV treatment (Supplementary Figure $\mathrm{S} 2 \mathrm{C} ; \mathrm{F}_{5,30}=0.42, P=0.8299$ ) or the timing of the injection. Behaviors were indistinguishable when compared with the similar group of animals injected before CPP (Supplementary Figure S2C; $F_{1,30}=1.13, P=0.2953$ ).

When cocaine-paired animals were given a single injection of low-dose cocaine, drug-induced place preference was immediately reinstated (Figure 4). The control LVGFP group and LV-miR-124-Sil group displayed cocaine CPP scores indistinguishable when compared with the similar group of animals, lentivirally injected before the establishment of cocaine CPP. Interestingly, LV-miR-124 expression after the establishment of cocaine CPP failed to attenuate the reinstatement of cocaine CPP as observed with the similar group when LV-miR-124 was injected before the establishment of cocaine CPP (Figure 4; $\mathrm{F}_{1,60}=0.73$, $P=0.3975)$. This suggests that miR-124 expression during the cocaine CPP acquisition period is crucial for suppressing the reinstating properties of cocaine. Clearly, once the cocaine CPP had been established, the overexpression of miR-124 had little effect thereafter on the reinstatement of cocaine CPP and was comparable to that of the control GFP group. 
Effect miRNA-124

Regulation on Cocaine CPP Reinstatement

miR-124 Cocaine Priming

LV-miR-124 regulation before CPP conditioning period

$\square$ LV-miR-124 regulation after CPP conditioning period

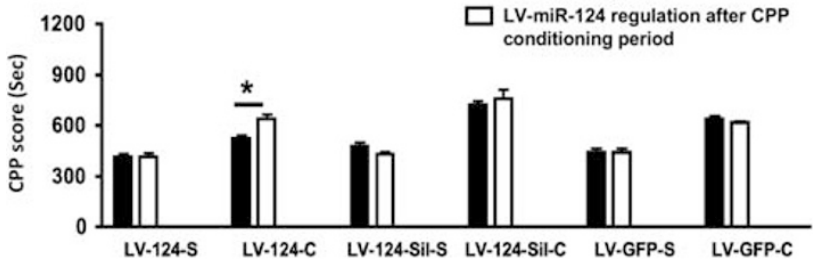

Figure 4 Effect of lentiviral vector (LV)-miR-I24 regulation on the reinstatement of cocaine-induced conditioned place preference (CPP). Four groups of animals $(n=12)$ were subjected to cocaine CPP. Immediately after the establishment of CPP, three groups were stereotaxically injected with either LV-miR-I24 or miR-124-Silencers (Sil) or control green fluorescent protein (GFP), a fourth retained as naive un-operated animals. LV-miR-I24 expression in the NAc after previous cocaine conditioning failed to attenuate the reinstating properties of cocaine. Silencing miR- 124 leads to an enhanced reinstatement of cocaine CPP compared with LV-GFP group, whether injected either previously or after cocaine CPP, whereas LV-miR-I 24 expression after previous cocaine conditioning results in reinstatement of CPP comparable to that of the control GFP and shows a significantly enhanced reinstatement compared with the similar group injected before cocaine conditioning. Values represent mean \pm SEM. $* P<0.05$, $* * P<0.0$ I, and $* * * P<0.00$ I represents values significantly different from the same cocaine paired corresponding LV-miRNA group injected either previously or after cocaine conditioning, by two-way analysis of variance (ANOVA), followed by Bonferroni post hoc tests.

\section{Behavioral Changes in Cocaine CPP are Mediated by} Localized miRNA Expression and Silencing in the Nac

To consolidate the correlation between localized miRNA regulations in the NAc with the observed behavioral changes after cocaine CPP, mature miRNA levels from the LV-miRNA expression and silencing groups were quantified (see Methods). Previous studies from our lab had established that the LV-mediated, ectopic expression of genes and siRNAs in the NAc are very clearly restricted along the needle tract of the injected area (Chandrasekar and Dreyer, 2010a,b). RNA from the microdissected NAc region was used for the quantification of mature miRNAs after the behavioral experiments. Results show a significant increase in the levels of mature forms of miR-124 (Figure 5a; $\mathrm{F}_{6,24}=14.74, P<0.0001$ ), miR-181a (Figure 5b; $\mathrm{F}_{6,24}=25.99$, $P<0.0001$ ), and let-7d (Figure 5c; $\mathrm{F}_{6,24}=25.55, P<0.0001$ ) in the LV-miR-124-, LV-miR-181a- and LV-let-7d-treated groups, respectively. LV-mediated expression of the silencers showed a significant, specific, and localized decrease in the levels of corresponding mature miRNAs. Significantly decreased mature levels of miR-124 $\left(\mathrm{F}_{3,24}=19.94\right.$, $P<0.0001)$, miR-181a $\left(\mathrm{F}_{3,24}=18.74, P<0.0001\right)$, and let-7d $(\mathrm{F} 3,24=20.80, P<0.0001)$ were observed in the LV-miR124-Sil-, LV-miR-181a-Sil, and LV-let-7d-Sil-treated groups, respectively. A small decrease in miR-124 was also observed with the LV-miR-124-Sil group treated with doxycycline, probably attributed to the slight leakiness of the system. Expression or silencing of a single miRNA did not affect the expression of the other two mature miRNA levels in the NAc, highlighting the specificity of the LV-mediated miRNA expression and silencing.
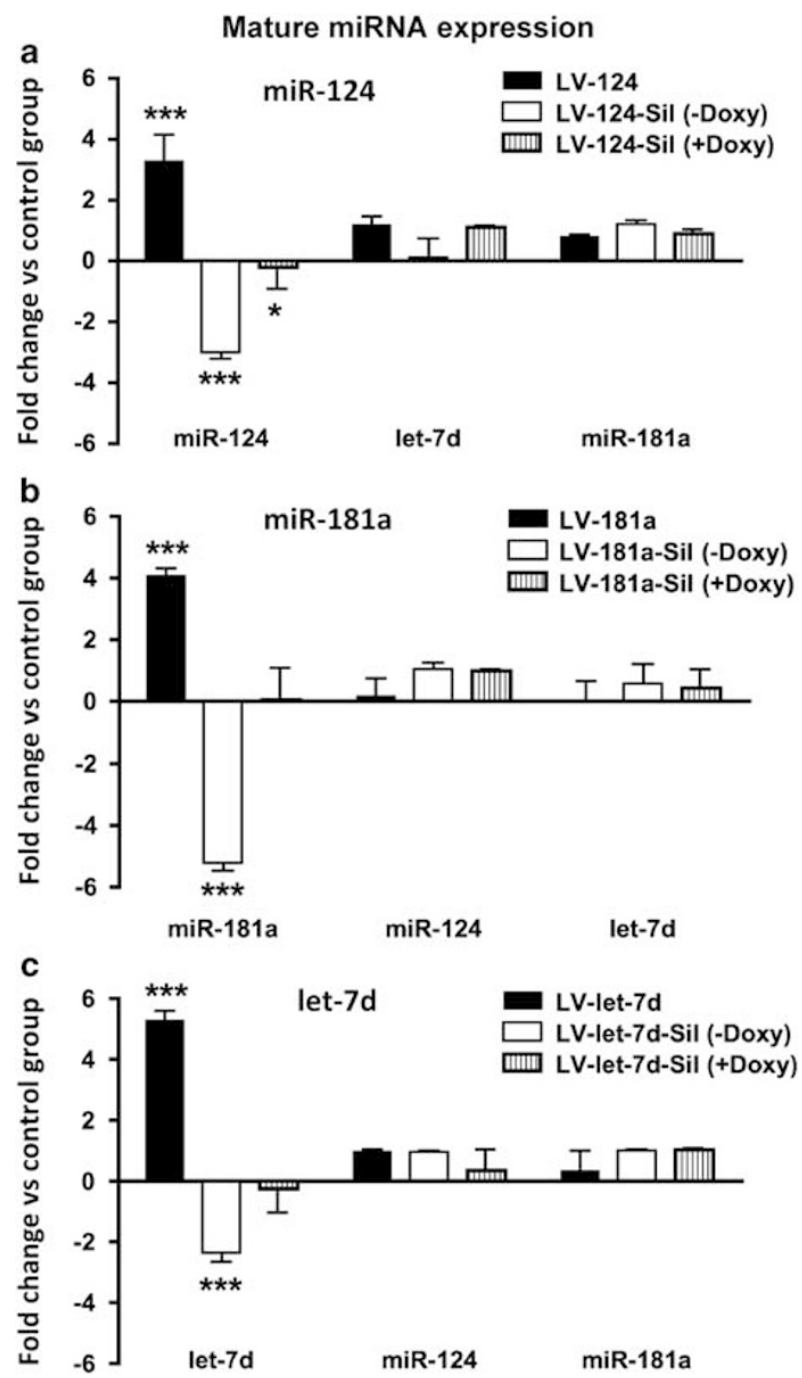

Figure 5 Quantitative real-time-polymerase chain reaction (qRT-PCR) shows specific expression or silencing of mature microRNAs (miRNAs) after lentiviral vector (LV)-miRNA regulation in the nucleus accumbens (NAc). Samples from rats bilaterally injected in the NAc with corresponding lentiviruses were analyzed at the end of the behavioral studies and used for quantification of mature miRNA levels (see Methods). (a) Quantification of mature miR-124 levels after LV-miR-124 and LV-miR-124-Silencers (Sil) expression in the presence (no expression) or absence (expression) of doxycycline. (b) Quantification of mature miR-I8Ia levels after LV-miR$18 \mathrm{Ia}$ and LV-miR-I8Ia-Sil expression in the presence or absence of doxycycline. (c) Quantification of mature let-7d levels after LV-let-7d and LV-let-7d-Sil expression in the presence or absence of doxycycline. Expression levels of mature miRNAs were calculated relative to U6 small nuclear RNA (snRNA) levels (see Methods) and represented as fold change compared with the control LV-GFP group. $* P<0.05$, $* * P<0.0$ I, and $* * * P<0.001$ represents values significantly different from LV-GFP group, by two-way analysis of variance (ANOVA), followed by Bonferroni post hoc tests.

To further correlate the LV-miRNA expression with the observed behavioral changes, we checked whether these miRNAs are modulated by cocaine in naive un-operated animals under the same cocaine CPP experimental conditions (Supplementary Figure S2). Mature miRNA quantification from the naive animals killed immediately after CPP, extinction, and reinstatement showed that miR-124, let-7d, 
and miR-181a are modulated by cocaine CPP. Significant downregulation of miR-124 (2.8-fold) and let-7d (2.2-fold) were observed after CPP (Supplementary Figure S2; $\mathrm{F}_{1,12}=1132.33, P<0.0001$ ), whereas miR-181a levels remained unaltered, when compared with the saline control. Reinstatement of cocaine CPP showed that miR-124 (1.8fold) and let-7d are significantly decreased, whereas miR181a was significantly induced (2.3-fold) (Supplementary Figure S2; $\left.\mathrm{F}_{1,12}=14.18, \quad P=0.0027\right)$. On the contrary, extinction resulted in no changes in the miRNA levels (Supplementary Figure S2; $\mathrm{F}_{1,12}=2.73, P=0.1245$ ), albeit a small non-statistically important increase in miR-124 levels.

\section{miRNA Regulation Modulates mRNA Expression of Target Plasticity Genes}

In addition to translational inhibition, miRNAs can downregulate a large number of target mRNAs (Lim et al, 2005; Baek et al, 2008; Selbach et al, 2008) and may play a major role in mRNA decay (Esslinger and Förstemann, 2009). To check this in the context of cocaine CPP, based on computational and available experimental data on miRNA-target gene interactions (Chandrasekar and Dreyer, 2009), we analyzed mRNA levels of various plasticity genes from the NAc region of different groups after the behavioral experiments (Figure 6 and Supplementary Tables S1 and S2).

The LV-miR-124-treated group showed no significant changes in the transcript levels of direct miR-124 targets like ITG $\beta 1$ and Drd3 compared with the control GFP group. Intriguingly, levels of BDNF, a direct target downregulated by miR-124 in our previous in vitro studies, remain unchanged after in vivo LV-miR-124 expression, highlighting the complexity of gene expression changes after cocaine administration in vivo. However, a strong increase in UPA and DAT levels was observed $\left(\mathrm{F}_{2,84}=183.36\right.$, $P<0.0001)$. On the other hand, silencing of miR-124 resulted in a nonsignificant increase in ITG $\beta 1$ and $\operatorname{Drd} 3$, but a very significant increase in $\Delta$ fos, together with an impressive decrease of many downstream genes, including FosB (eightfold decrease), MeCP2 (10-fold decrease), seven zinc-finger myelin transcription factor-1 (7MYT1)/NZF-2b (1.5-fold), and GRIA2 (twofold) (Figure 6a; $\mathrm{F}_{26,84}=34.60$, $P<0.0001)$. In addition, mRNA levels of some targets were also decreased after silencing miR-124, such as BDNF (sixfold) and NAC1 (fivefold). Furthermore, our results show that miR-124 regulation also affects the mRNA levels of Ptbp1 and Ptbp2 (data not shown) in the NAc. LV-miR124 expression resulted in a significant reduction in the transcript levels of Ptbp1, whereas silencing did not cause any changes. On the other hand, Ptbp2 levels remained unchanged after LV-miR-124 expression, whereas silencing miR-124 resulted in a significant decrease in the Ptbp2 levels (data not shown).

The LV-miR-181a-treated group displayed a significant change in the expression levels of many direct and indirect targets (Figure $6 \mathrm{~b} ; \mathrm{F}_{26,84}=20.23, P<0.0001$ ). A significant decrease was observed in Per2 levels (a direct target of miR181a) and also in Drd2, Drd3, and 7MYT1/NZF-2b (indirect targets; $\left.F_{2,84}=7.68, P=0.0009\right)$. Silencing of miR-181a resulted in a significant decrease of NAC1 (3.5-fold), Drd2, and uPA mRNA levels. Moreover, MeCP2 levels were significantly increased (threefold) after miR-181a overexpression, whereas silencing resulted in a significant decrease (threefold). Conversely, miR-181a overexpression resulted in a significant decrease in DAT expression and a significant increase upon silencing miR-181a. Transcript levels of other direct targets such as GRIA2 and GRM5 remained unchanged after miR-181a silencing or overexpression.

The LV-let-7d-treated group showed significant changes in the mRNA levels of some direct targets like MOR1, Drd3 (threefold decrease) (Figure $6 \mathrm{c} ; \mathrm{F}_{2,84}=48.87, P<0.0001$ ), and also a significant downregulation of BDNF (twofold decrease), 7MYT1/NZF-2b (threefold decrease), and GRIA2, but no change on uPA levels and a very significant increase in DAT levels (threefold) $\left(\mathrm{F}_{26,84}=12.68, P<0.0001\right)$. Silencing let-7d resulted in a significant decrease of NAC1 (fivefold), and Per2 (threefold), together with a significant increase in the levels of $\Delta$ fos (2.5-fold). BDNF, GRIA2, and MeCP2 displayed decreased mRNA levels compared with the control GFP group, regardless of overexpression or silencing, suggesting a nonspecific downstream effect. It is interesting to note that the mature miR-124 and let-7d, surprisingly, shows a four-nucleotide shared seed sequence homology and a three-nucleotide homology, adjacent to the seed sequence with significant overlapping target genes (Supplementary Figure S1B) by miR and a target prediction (http://www.microrna.org) (Betel et al, 2008).

\section{LV-miRNA Regulation Modulates the Expression of Several Plasticity Genes at the Protein Level}

To further investigate gene regulation by miR-124, miR$181 \mathrm{a}$, and let-7d in cocaine-CPP, protein levels of key genes were quantified compared with the controls groups. Direct and indirect target protein expression in the NAc region of the respective LV-miRNA-treated groups were analyzed after the CPP experiment by western blots and quantified by densitometric analysis normalized to $\beta$-actin (see Methods). Although analyzing all the potential targets of each miRNAs at the protein level is beyond the scope of this study, the few proteins analyzed displayed strong regulation (Figure 7 and Supplementary Tables S1 and S2).

Regulation of miR-124 in the NAc affected the protein levels of various direct and indirect target genes (Figure 7a; $\left.\mathrm{F}_{18,56}=33.10, P<0.0001\right)$. miR-124 overexpression resulted in a small, nonsignificant decrease in CREB protein (a direct miR-124 target) when compared with the control GFP group; on the contrary, silencing of miR-124 resulted in a significant increase of $\mathrm{CREB}\left(\mathrm{F}_{6,56}=74.42, P<0.0001\right)$. Under these conditions, miR-124 expression or silencing caused no significant change in the level of phosphorylated (serine 133) cAMP-responsive element binding protein (pCREB), but a significant decrease in FosB upon silencing. Correlating with mRNA expression, a significant increase in uPA and DAT protein levels was observed upon miR-124 overexpression, and a decrease in $\operatorname{EphB1}\left(\mathrm{F}_{3,56}=3.21\right.$, $P=0.0296)$.

miR-181a, on the other hand, enhanced cocainecue-induced stimuli by regulating the protein levels of several direct and indirect genes like DAT, MOR1, and Per2 (Figure $7 \mathrm{~b} ; \mathrm{F}_{15,48}=23.01, P<0.0001$ ). We observed that miR-181a expression changes in the NAc did not affect CREB, pCREB, or FosB levels. However, miR-181a 
a

Expression changes in NAC after

LV-miR-124 or LV-miR-124-Sil injection

LV-124

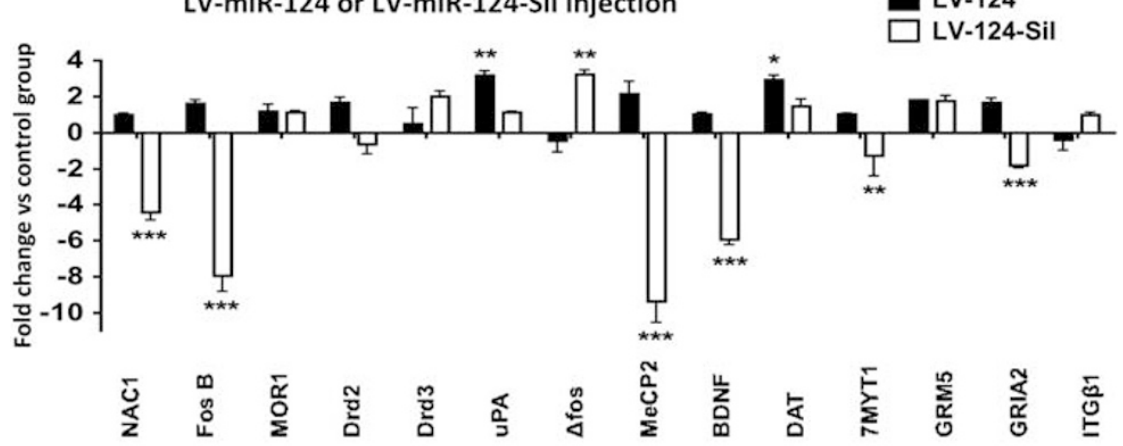

b Expression changes in NAc after

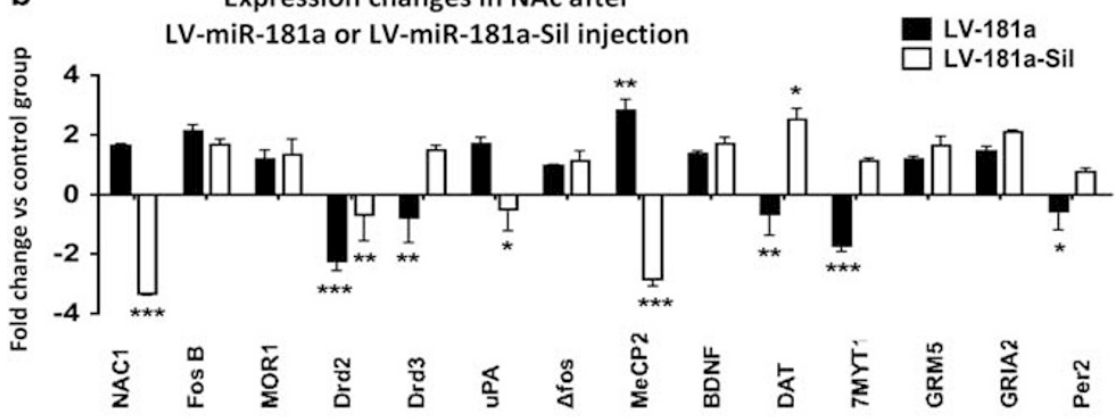

C Expression changes in NAc after LV-let-7d or LV-let-7d-Sil injection

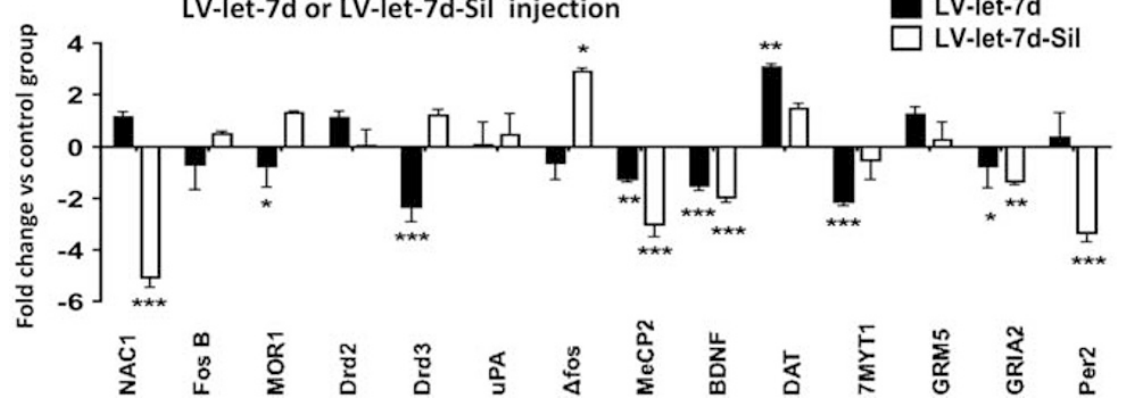

Figure 6 Differential expression of miR-124, let-7d, and miR-181a in the nucleus accumbens (NAc) alters mRNA expression of target genes. Reverse transcription-polymerase chain reaction (RT-PCR) quantification of cocaine-induced and plasticity-related microRNA (miRNA) target genes, after lentiviralmediated regulation of miR-I24 (a), miR-18Ia (b), and let-7d (c) transcript levels. Rats ( $n=12 /$ group) were bilaterally injected into the NAc with either lentiviral vector (LV)-miRNA or the corresponding LV-miRNA-Silencer or LV-green fluorescent protein (GFP) (see Methods). Expression levels were calculated relative to cyclophilin and represented as fold change compared with the LV-GFP control group. $* P<0.05$, $* * P<0.01$, and $* * * P<0.00$ I represents values significantly different from LV-GFP-injected rats, by two-way analysis of variance (ANOVA), followed by Bonferroni post hoc tests.

overexpression resulted in a fourfold decrease in DAT protein levels (Figure $7 \mathrm{~b} ; \mathrm{F}_{3,48}=21.31, P<0.0001$ ), with no effect on Per2 (a direct miR-181a target), whereas silencing miR-181a resulted in a significant increase of Per2 (75\% more) and significant decrease of MOR1 (25\% less) protein levels.

Finally, let-7d regulation also affected protein levels of various direct or indirect let-7d targets genes (Figure $7 \mathrm{c}$; $\left.\mathrm{F}_{18,56}=22.48, P<0.0001\right)$. Let-7d overexpression resulted in a very strong decrease of Drd3 protein levels, correlating with our previous in vitro observation (Chandrasekar and Dreyer, 2009); however, although it is a direct let-7d target, silencing did not alter the expression. A fivefold decrease of MOR1 $\left(\mathrm{F}_{3,56}=84.85, P<0.0001\right)$ - another direct target was observed upon let-7d overexpression, with a significant increase after let-7d silencing $\left(\mathrm{F}_{6,56}=39.42\right.$,
$P<0.0001)$. Let-7d overexpression also resulted in a significant increase in DAT. Furthermore, although let-7d regulation did not affect the basal CREB protein levels, silencing let-7d resulted in a significant increase in the pCREB (serine-133). Finally, FosB protein showed a nonsignificant decrease after let-7d overexpression, whereas silencing resulted in $>2$-fold increase in FosB levels.

\section{DISCUSSION}

Localized lentiviral-mediated expression of specific miRNAs and their corresponding miRNA silencers enables a thorough insight into the role of cocaine-responsive miRNAs and associated regulatory pathways in the NAc. 


\section{Protein expression changes in NAc after miRNA regulation}
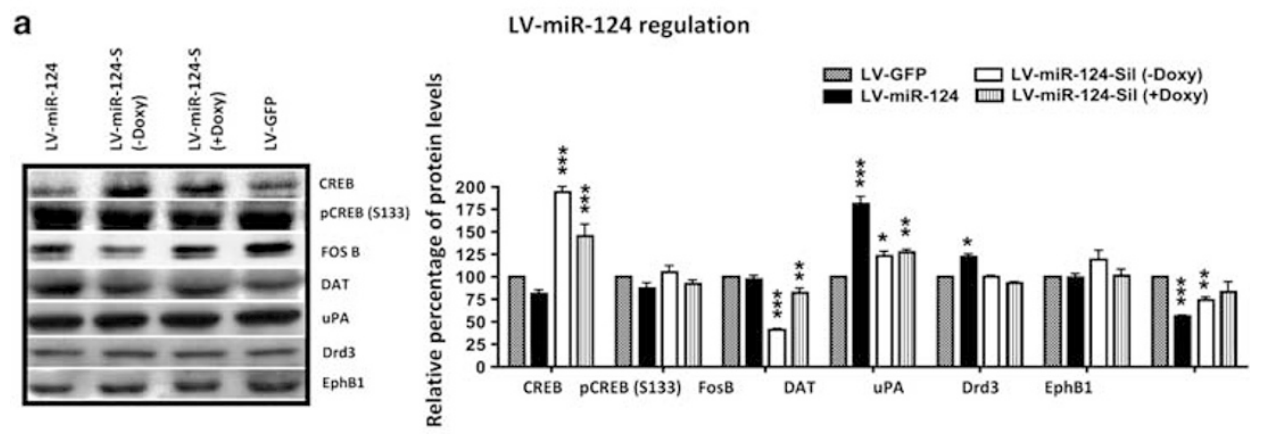

b
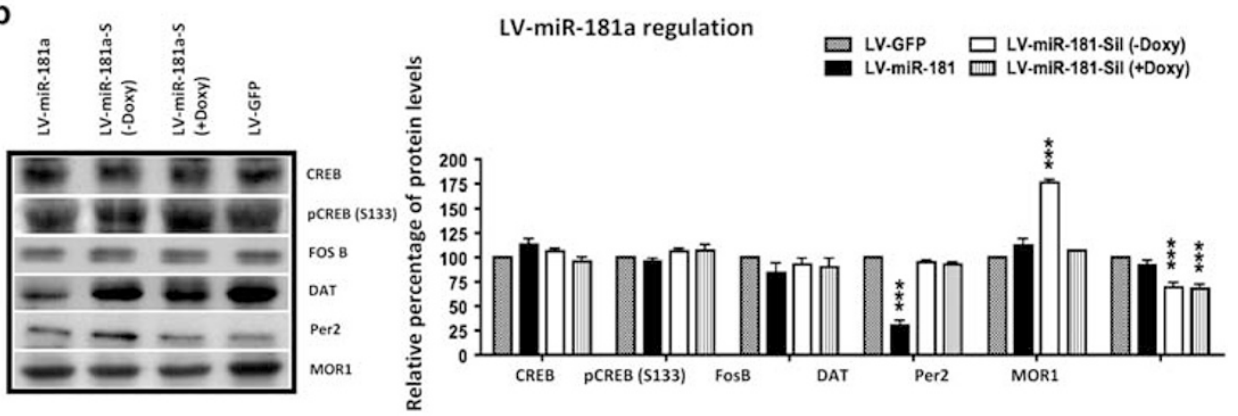

C

LV-let-7d regulation
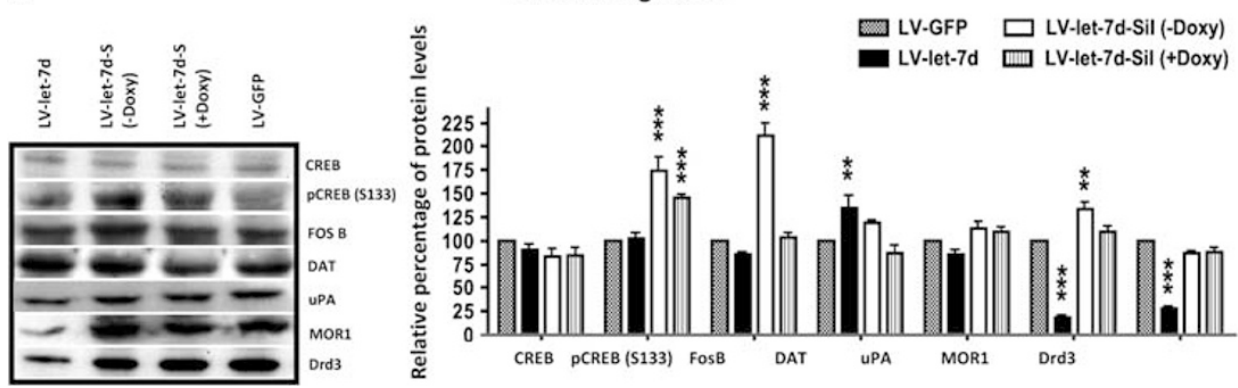

Figure 7 miR-124, let-7d, and miR-18 I cause changes at protein levels of miRNA targets genes after cocaine treatment. Immunoblots (left panels) and corresponding protein quantification graphs (right panels) display widespread changes in protein levels of several cocaine- and plasticity-related genes after lentiviral vector (LV)-mediated regulation of miR-I24 (a), miR-I8Ia (b), and let-7d (c) upon cocaine treatment. Protein levels were quantified from rats bilaterally injected into the nucleus accumbens (NAc) with either LV-miRNA or the corresponding LV-miRNA-Silencer or LV-green fluorescent protein (GFP) (see Methods). Expression levels were calculated relative to $\beta$-actin as control and represented as fold change compared with the LV-GFP group. Graphs on the right show densitometric quantification of the corresponding band intensities relative to the loading control. $* P<0.05$, $* * P<0.0 \mathrm{l}$, and $* * * * P<0.00$ I represents values significantly different from LV-GFP-injected rats, by two-way analysis of variance (ANOVA), followed by Bonferroni post hoc tests.

Our data show that localized miR-124 and let-7d expression significantly attenuates cocaine-induced $\mathrm{CPP}$, whereas overexpression of miR-181a potently enhances it. Conversely, LV-mediated miR-124 and let-7d inhibition by their corresponding silencers resulted in enhanced CPP to cocaine, whereas silencing of miR-181a results in strong attenuation. The behavioral effects were abolished when the silencer expression has been turned off with doxycycline, pointing to the specificity of the miRNA silencing in terms of behavioral changes. These effects were specifically mediated by ectopic increase in corresponding miRNAs or decrease by silencer expression, as shown by miR-qRTPCR. The molecular neuroadaptation occurs via alteration in several direct and indirect plasticity-related target genes both at the mRNA and protein levels.

This suggests that regulation of miR-124, let-7d, and miR-181a in the NAc is a critical component for the development of cocaine-induced CPP. Depending upon downstream expression changes of plasticity genes by the miRNAs after drug administration, the reward value for cocaine is apparently more salient in miR-181a-treated rats and attenuated in miR-124- and let-7d-treated rats, as they target different plasticity genes. These changes may also affect learning and association between the cues and the reward.

Our results show that miR-124 and let-7d expression and miR-181a silencing increased both the rate of extinction (as seen by fewer extinction sessions needed) as well as the persistence of extinction (as observed by the weakened reinstatement following a post-extinction priming injection of cocaine). Conversely, overexpression of miR-181a and silencing of miR-124 and let-7d leads to delayed extinction of cocaine CPP, which is likely due to the high starting point, rather than due to alteration in extinction. 
miRNA-induced gene expression changes probably leads to destabilization of contextual memory traces and facilitation of extinction learning. By virtue of augmenting the preference to a cocaine-associated context, expression of miR-181a or silencing of miR-124 and let-7d prolongs, but does not maintain, the behavioral inclination for cocaine context in the absence of the drug (as shown by normal extinction).

Reinstatement of cocaine-seeking behavior occurs after drug priming and craving is triggered after re-exposure to the drug (De Wit and Stewart, 1981; Shaham et al, 2003). This study suggests that the cocaine cue may have greater salience or greater retention in the groups where miR-124 and let-7d are silenced, because they showed longer time to extinguish CPP to cocaine and exhibited a stronger reinstatement upon priming. Intriguingly, the miR-181a overexpression group, albeit showing longer time for CPP extinction, failed to show significant reinstatement of cocaine CPP compared with control group, which may be due to failure in retention of the learning experience. Longlived molecular adaptations and regulation of protein translation in response to dopamine stimulation by cocaine contribute to pathological memory processes underlying addiction (Hyman, 2005). This suggests the importance of neuronal miRNA-mediated translation control in maladaptive memory formation.

A second set of experiments performed to check the effects of miR-124 regulation, after the contextual memories of cocaine CPP were established, showed that miR-124 expression at the time of cocaine CPP acquisition is crucial for attenuating the reinstating properties of cocaine. miR124 expression after previous cocaine conditioning of the animals resulted in CPP comparable to that of the GFP control, which itself remained unchanged regardless of LV injection before or after cocaine CPP. Also our data show that $\mathrm{miR}-124$ and let-7d are suppressed after CPP and during the reinstatement in naive animals, whereas the miR-181a levels are induced after reinstatement, and the levels of these miRNAs remained unchanged during the extinction of CPP. These observations suggest that downregulation of miR-124 may enhance the maladaptive drug-associated memories (regardless of previous conditioning of the animals), in line with the findings that miR-124 inhibition act as the switch necessary to convert short-term facilitation into long-term facilitation in Aplysia (Rajasethupathy et al, 2009). One caveat of this correlation is the marked divergence in anatomy and behavior of serotonergic system between Aplysia and mammals, despite considerable conservation in serotonergic function.

\section{miRNA Expression and Silencing In Vivo}

For our study, we developed doxycycline-regulatable lentiviruses expressing four complementary pMREs as target sequences for specific individual miRNAs in the 3'-UTR of EGFP, enabling for localized, stable, and regulatable miRNA silencing (Chandrasekar and Dreyer, 2009). Stable in vivo miRNA knockdown can be achieved using perfect (miRT or pMREs) or imperfect target sequences complementary to an miRNA (Ebert et al, 2007; Scherr et al, 2007; Care et al, 2007; Gentner et al, 2009), expressed by LVs specifically affecting the targeted miRNAs without saturating the effector pathway (Gentner et al, 2009). As pMRE sites containing transcripts are directly degraded by miRISC (RNA-induced silencing complex) (Hutvagner and Zamore, 2002; Liu et al, 2004) and as miRISC has a high catalytic rate (Haley and Zamore, 2004), there is less likelihood of miRISC saturation (Brown et al, 2007). Studies by Gentner et al (2009) show only a modest decrease of targeted miRNAs, whereas a significant reduction in the target miRNA levels were obtained using lentivirally expressed antagomirs (Scherr et al, 2007). Our qRT-PCR results show a significant and specific downregulation (two- to fivefold) of the mature miRNAs levels targeted by corresponding silencers correlating with the recent reports that perfect match targets downregulate miRNA levels (Cazalla et al, 2010; Ameres et al, 2010). One caveat of silencing let-7d-like miRNAs belonging to seed match family is that there is an inadvertent risk of interfering with the activity of other members. Nevertheless, miRNA levels correlate with the miRNA functions in observed cocaine-induced behavioral changes.

Apart from translational repression, miRNAs can also cause degradation of the target mRNAs. In vitro overexpression of miR-124 decreases the transcripts of 174 genes (Lim et al, 2005) and some studies suggest that translational inhibition plays only a minor role (Baek et al, 2008; Selbach et al, 2008; Esslinger and Förstemann, 2009). This would explain the decrease in the transcript levels of direct and indirect target genes observed by qRT-PCR, which for most genes, correlates with the protein levels found in western blots. Intriguingly, NAC1 mRNA levels are downregulated regardless of the miRNA silencer used.

miR-124 is involved in neuronal differentiation and plasticity (Lim et al, 2005; Makeyev et al, 2007; Visvanathan et al, 2007). miR-124 targets PTBP1, an alternative premRNA splicing repressor and Cdc42 in neurite outgrowth and neuronal specification (Makeyev et al, 2007; Chang et al, 2009; Yu et al, 2008). Neuroadaptations to cocaine induce alternative splicing of gene transcripts resulting in differentially expressed mRNAs encoding functionally antagonistic proteins (Mumberg et al, 1991). We found decreased Ptbp1 mRNAs after miR-124 expression and increased Ptbp2 levels after miR-124 silencing (data not shown), which suggests that miR-124-mediated suppression of alternate splicing mechanisms is crucial for molecular adaptations to cocaine. Mature miR-124 (but not the precursor) is rapidly inhibited by serotonin and this miR-124 inhibition is crucial for long-term synaptic facilitation, by regulating CREB via MAPK signaling (Rajasethupathy et al, 2009). We found previously that chronic cocaine administration results in significant inhibition of mature miR-124 levels, but not the precursor (Chandrasekar and Dreyer, 2009). These results furthermore show that CREB levels were elevated in the NAc after miR-124 silencing, whereas pCREB levels in the NAc were elevated after LV-let-7d silencing, suggesting that miR-124 and let-7d suppression are crucial to cocaine-induced plasticity. Nuclear activation of CREB plays an important function in converting short-term into long-term plasticity associated with learning and addiction (Barco et al, 2002; Carlezon et al, 2005). miR-124 is involved in a feedback loop with CREB and REST (Wu and Xie, 2006; Conaco et al, 2006), and here we show that miR-124 regulates several 
direct and indirect target genes at the mRNA ( $\Delta$ fos, MeCP2, 7Myt1, GRIA2) and at the protein levels (Supplementary Tables S1 and S2), particularly FosB, DAT, uPA, as well as EphB1 - whose ligand Ephrin-B1 is also regulated by miR-124 (Arvanitis et al, 2010). Intriguingly, it is as of yet unclear as to why the downregulation of BDNF by miR-124 as observed in in vitro studies (Chandrasekar and Dreyer, 2009) was not observed in this in vivo studies. We found that miR-181a regulates Per2 and DAT at both mRNA as well as protein levels, whereas MOR1 is regulated only at protein levels (Figure $7 \mathrm{~b}$ ). In contrast, let-7d regulation induces expression changes in MOR1, Drd3, uPA, $\Delta$ fos, DAT, 7Myt1, BDNF, GRIA2, MeCP2, and Per2 at the mRNA level (Figure $6 \mathrm{c}$ and Supplementary Tables S1 and S2); western blot analysis confirms that let-7d regulates FosB, Drd3, MOR1, and DAT at the protein levels (Supplementary Tables S1 and S2). Let-7d regulates the phosphorylation of CREB without changing basal CREB protein levels. Western blots corroborates with results found at mRNA levels for Drd3 and MOR1 (direct targets of let-7d) and DAT (an indirect target). These results support the finding that Let-7 is involved in regulating synapse maturation, growth, and dendritic arborization (Caygill and Johnston 2008). miR-124 and let-7d share overlapping gene targets and show a four-nucleotide seed sequence similarity and a three-nucleotide homology near the seed; this suggests that both miRNAs might share several 'category two' target genes (implying week seed pairing compensated by strong base pairing to the $3^{\prime}$ end; Bartel, 2009), further supporting the similar behavior outcome by LV expression of these miRNAs in cocaine CPP.

The discrepancy observed between the mRNA and protein levels may be due to various factors: long-lived protein stability, rate of transcription, and stability of individual mRNAs. The data clearly highlights the dynamic regulation by miRNAs on their targets in cocaine-induced molecular adaptations. Interpretation of the observed changes in gene transcripts is complicated, as the data also reflect secondary effects. The effects may also be indirectly caused by the miRNA through the deregulation of a direct target like a transcription factor (CREB, FosB, Myt1, NAC1, and so on) and could result from altered transcriptional output and hyper-repression of the transcription factors (Esslinger and Förstemann, 2009). In general, our data strongly support recent studies where miR-212 with homeostatic interactions with $\mathrm{MeCP} 2$ has been reported to be upregulated in the dorsal striatum upon extended (but not restricted) cocaine access and regulates vulnerability to cocaine addiction (Hollander et al, 2010; Im et al, 2010).

Drugs of abuse produce pathological changes to the brain that can endure even after long-term cessation of drug use (Hyman and Malenka, 2001; Kalivas and O'Brien,2008). In this context, our study provides a unique perspective shedding light on the role of miRNAs and post-transcriptional control events on molecular adaptation to cocaine. Our findings suggest a possible function of miRNAs in determining both the reward value of the drug and protein synthesis-dependent maladaptive drug-associated memories processes. Overall, our findings indicate that the miRNAs in the NAc exert a complex regulatory influence over the incentive motivational effects of cocaine-induced place preference. Identifying molecular cues responsive for long-lasting neuroadaptive changes along with environmental and neurobiological mechanisms underlying addiction and relapse consequently may lead to new potential pharmacological interventions against addiction.

\section{ACKNOWLEDGEMENTS}

We are grateful to Mrs C Deforel-Poncet for skilful assistance. This study was supported by Swiss National Foundation Grants 3100-059350, 3100AO-100686, and 31003A-116492 (JLD). The funders had no role in study design, data collection and analysis, decision to publish, or preparation of the manuscript.

\section{DISCLOSURE}

The authors declare no conflict of interest.

\section{REFERENCES}

Ambros V (2004). The functions of animal microRNAs. Nature 431: 350-355.

Ameres SL, Horwich MD, Hung JH, Xu J, Ghildiyal M, Weng Z et al (2010). Target RNA-directed trimming and tailing of small silencing RNAs. Science 328: 1534-1539.

Artinian J, De Jaeger X, Fellini L, de Saint Blanquat P, Roullet P (2007). Reactivation with a simple exposure to the experimental environment is sufficient to induce reconsolidation requiring protein synthesis in the hippocampal CA3 region in mice. Hippocampus 17: 181-191.

Arvanitis DN, Jungas T, Behar A, Davy A (2010). Ephrin-B1 reverse signaling controls a posttranscriptional feedback mechanism via miR-124. Mol Cell Biol 30: 2508-2517.

Ashraf SI, McLoon AL, Sclarsic SM, Kunes S (2006). Synaptic protein synthesis associated with memory is regulated by the RISC pathway in Drosophila. Cell 124: 191-205.

Baek D, Villén J, Shin C, Camargo FD, Gygi SP, Bartel DP (2008). The impact of microRNAs on protein output. Nature 455: 64-71.

Bahi A, Boyer F, Chandrasekar V, Dreyer JL (2008a). Role of accumbens BDNF and TrkB in cocaine-induced psychomotor sensitization, conditioned-place preference, and reinstatement in rats. Psychopharmacology 199: 169-182.

Bahi A, Kusnecov AW, Dreyer JL (2008b). Effects of urokinasetype plasminogen activator in the acquisition, expression and reinstatement of cocaine-induced conditioned-place preference. Behav Brain Res 191: 17-25.

Barco A, Alarcon JM, Kandel ER (2002). Expression of constitutively active CREB protein facilitates the late phase of long-term potentiation by enhancing synaptic capture. Cell 108: 689-703.

Bartel DP (2004). MicroRNAs: genomics, biogenesis, mechanism, and function. Cell 116: 281-297.

Bartel DP (2009). MicroRNAs: target recognition and regulatory functions. Cell 136: 215-233.

Bernardi RE, Lattal KM, Berger SP (2007). Anisomycin disrupts a contextual memory following reactivation in a cocaine-induced locomotor activity paradigm. Behav Neurosci 121: 156-163.

Betel D, Wilson M, Gabow A, Marks DS, Sander C (2008). The microRNA.org resource: targets and expression. Nucleic Acids Res 36: D149-D153.

Bhattacharyya SN, Habermacher R, Martine U, Closs EI, Filipowicz W (2006). Relief of microRNA-mediated translational repression in human cells subjected to stress. Cell 125: 1111-1124.

Blencowe BJ (2006). Alternative splicing: new insights from global analyses. Cell 126: 37-47. 
Boyer F, Dreyer JL (2007). Alpha-synuclein in the nucleus accumbens induces changes in cocaine behaviour in rats. Eur J Neurosci 26: 2764-2776.

Care A, Catalucci D, Felicetti F, Bonci D, Addario A, Gallo P et al (2007). MicroRNA-133 controls cardiac hypertrophy. Nat Med 13: $613-618$.

Carlezon Jr WA, Duman RS, Nestler EJ (2005). The many faces of CREB. Trends Neurosci 28: 436-445.

Caygill EE, Johnston LA (2008). Temporal regulation of metamorphic processes in Drosophila by the let-7 and miR-125 heterochronic microRNAs. Curr Biol 18: 943-950.

Cazalla D, Yario T, Steitz J (2010). Down-regulation of a host microRNA by a Herpesvirus saimiri noncoding RNA. Science; 328: $1563-1566$.

Chandrasekar V, Dreyer JL (2009). microRNAs miR-124, let-7d and miR-181a regulate cocaine-induced plasticity. Mol Cell Neurosci 42: 350-362.

Chandrasekar V, Dreyer JL (2010a). The brain-specific neural zinc finger transcription factor $2 \mathrm{~b}$ (NZF-2b/7ZFMyt1) causes suppression of cocaine-induced locomotor activity. Neurobiol Dis 37: 86-98.

Chandrasekar V, Dreyer JL (2010b). The brain-specific neural zinc finger transcription factor $2 \mathrm{~b}$ (NZF-2b/7ZFMyt1) suppresses cocaine self-administration in rats. Front Behav Neurosci 4: $14-22$.

Chang S, Wen S, Chen D, Jin P (2009). Small regulatory RNAs in neurodevelopmental disorders. Hum Mol Genet 18(Suppl R1): R18-R26.

Conaco C, Otto S, Han JJ, Mandel G (2006). Reciprocal actions of REST and a microRNA promote neuronal identity. Proc Natl Acad Sci USA 103: 2422-2427.

De Wit H, Stewart J (1981). Reinstatement of cocaine-reinforced responding in the rat. Psychopharmacology (Berl) 75: 134-143.

Ebert MS, Neilson JR, Sharp PA (2007). MicroRNA sponges: competitive inhibitors of small RNAs in mammalian cells. Nat Methods 4: 721-726.

Esslinger S, Förstemann K (2009). MicroRNAs repress mainly through mRNA decay. Angew Chem Int Ed Engl 48: 853-855.

Farh KK, Grimson A, Jan C, Lewis BP, Johnston WK, Lim LP et al (2005). The widespread impact of mammalian microRNAs on mRNA repression and evolution. Science 310: 1817-1821.

Filipowicz W, Bhattacharyya SN, Sonenberg N (2008). Mechanisms of post-transcriptional regulation by microRNAs: are the answers in sight? Nat Rev Genet 9: 102-114.

Gentner B, Schira G, Giustacchini A, Amendola M, Brown BD, Ponzoni $\mathrm{M}$ et al (2009). Stable knockdown of microRNA in vivo by lentiviral vectors. Nat Methods 6: 63-66.

Grabowski PJ, Black DL (2001). Alternative RNA splicing in the nervous system. Prog Neurobiol 65: 289-308.

Haley B, Zamore PD (2004). Kinetic analysis of the RNAi enzyme complex. Nat Struct Mol Biol 11: 599-606.

Hellemans KG, Everitt BJ, Lee JL (2006). Disrupting reconsolidation of conditioned withdrawal memories in the basolateral amygdala reduces suppression of heroin seeking in rats. J Neurosci 26: 12694-12699.

Hollander JA, Im H, Amelio AL, Kocerha J, Bali P, Lu Q et al (2010). Striatal microRNA controls cocaine intake through CREB signaling. Nature 466: 197-202.

Huang W, Li MD (2008). Nicotine modulates expression of miR-140*, which targets the $3^{\prime}$-untranslated region of dynamin 1 gene (Dnm1). Int J Neuropsychopharmacol 10: 1-10.

Hutvagner G, Zamore PD (2002). A microRNA in a multipleturnover RNAi enzyme complex. Science 297: 2056-2060.

Hyman SE (2005). Addiction: a disease of learning and memory. Am J Psychiatry 162: 1414-1422.

Hyman SE, Malenka RC (2001). Addiction and the brain: the neurobiology of compulsion and its persistence. Nat Rev Neurosci 2: 695-703.
Im HI, Hollander JA, Bali P, Kenny PJ (2010). MeCP2 controls BDNF expression and cocaine intake through homeostatic interactions with microRNA-212. Nat Neurosci 13: 1120-1127.

Itzhak Y, Martin JL (2002). Cocaine-induced conditioned place preference in mice: induction, extinction and reinstatement by related psychostimulants. Neuropsychopharmacology 26: 130-134.

Johnston RJ, Hobert O (2003). A microRNA controlling left/right neuronal asymmetry in Caenorhabditis elegans. Nature 426: 845-849.

Kalivas PW, O'Brien C (2008). Drug addiction as a pathology of staged neuroplasticity. Neuropsychopharmacology 33: 166-180.

Kosik KS (2006). The neuronal microRNA system. Nat Rev Neurosci 7: 911-920.

Lee JL, Di Ciano P, Thomas KL, Everitt BJ (2005). Disrupting reconsolidation of drug memories reduces cocaine-seeking behavior. Neuron 47: 795-801.

Lee JL, Milton AL, Everitt BJ (2006). Cue-induced cocaine seeking and relapse are reduced by disruption of drug memory reconsolidation. J Neurosci 26: 5881-5887.

Lim LP, Lau NC, Garrett-Engele P, Grimson A, Schelter JM, Castle J et al (2005). Microarray analysis shows that some microRNAs downregulate large numbers of target mRNAs. Nature 433: 769-773.

Liu J, Carmell MA, Rivas FV, Marsden CG, Thomson JM, Song JJ et al (2004). Argonaute 2 is the catalytic engine of mammalian RNAi. Science 305: 1437-1441.

Makeyev EV, Zhang J, Carrasco MA, Maniatis T (2007). The MicroRNA miR-124 promotes neuronal differentiation by triggering brain-specific alternative pre-mRNA splicing. Mol Cell 27: 435-448.

McClung CA, Nestler EJ (2008). Neuroplasticity mediated by altered gene expression. Neuropsychopharmacology 33: 3-17.

Mueller D, Stewart J (2000). Cocaine-induced conditioned place preference: reinstatement by priming injections of cocaine after extinction. Behav Brain Res 115: 39-47.

Mumberg D, Lucibello FC, Schuermann M, Müller R (1991). Alternative splicing of fosB transcripts results in differentially expressed mRNAs encoding functionally antagonistic proteins. Genes Dev 5: 1212-1223.

Nestler EJ (2008). Review. Transcriptional mechanisms of addiction: role of DeltaFosB. Philos Trans $R$ Soc Lond Ser B 363: 3245-3255.

Paxinos, Watson (1998). The Rat Brain in Stereotaxic Coordinates, 4th edn. Academic Press: San Diego, CA.

Pietrzykowski AZ, Friesen RM, Martin GE, Puig SI, Nowak CL, Wynne PM et al (2008). Posttranscriptional regulation of BK channel splice variant stability by miR- 9 underlies neuroadaptation to alcohol. Neuron 59: 274-287.

Rajasethupathy P, Fiumara F, Sheridan R, Betel D, Puthanveettil SV, Russo JJ et al (2009). Characterization of small RNAs in aplysia reveals a role for miR-124 in constraining synaptic plasticity through CREB. Neuron 63: 803-817.

Rogers JL, See RE (2007). Selective inactivation of the ventral hippocampus attenuates cue-induced and cocaine-primed reinstatement of drug-seeking in rats. Neurobiol Learn Mem 87: 688-692.

Rybak A, Fuchs H, Smirnova L, Brandt C, Pohl EE, Nitsch R et al (2008). A feedback loop comprising lin-28 and let-7 controls prelet-7 maturation during neural stem-cell commitment. Nat Cell Biol 10: 987-993.

Schaefer A, Im HI, Ven $\varnothing$ MT, Fowler CD, Min A, Intrator A et al (2010). Argonaute 2 in dopamine 2 receptor-expressing neurons regulates cocaine addiction. J Exp Med 207: 1843-1851.

Scherr M, Venturini L, Battmer K, Schaller-Schoenitz M, Schaefer D, Dallmann I et al (2007). Lentivirus-mediated antagomir expression for specific inhibition of miRNA function. Nucleic Acids Res 35: e149. 
Schratt G (2009). Fine-tuning neural gene expression with microRNAs. Curr Opin Neurobiol 19: 213-219.

Schratt GM, Tuebing F, Nigh EA, Kane CG, Sabatini ME, Kiebler M et al (2006). A brain-specific microRNA regulates dendritic spine development. Nature 439: 283-289.

Selbach M, Schwanhäusser B, Thierfelder N, Fang Z, Khanin R, Rajewsky N (2008). Widespread changes in protein synthesis induced by microRNAs. Nature 455: 58-63.

Shaham Y, Shalev U, Lu L, De Wit H, Stewart J (2003). The reinstatement model of drug relapse: history, methodology and major findings. Psychopharmacology (Berl) 168: 3-20.

Siegel G, Obernosterer G, Fiore R, Oehmen M, Bicker S, Christensen $\mathrm{M}$ et al (2009). A functional screen implicates microRNA-138-dependent regulation of the depalmitoylation enzyme APT1 in dendritic spine morphogenesis. Nat Cell Biol 11: 705-716.

Vasudevan S, Tong Y, Steitz JA (2007). Switching from repression to activation: microRNAs can up-regulate translation. Science 318: 1931-1934.

Visvanathan J, Lee S, Lee B, Lee JW, Lee SK (2007). The microRNA miR-124 antagonizes the anti-neural REST/SCP1 pathway during embryonic CNS development. Genes Dev 21: 744-749.

Wu J, Xie X (2006). Comparative sequence analysis reveals an intricate network among REST, CREB and miRNA in mediating neuronal gene expression. Genome Biol 7: R85.

Yu JY, Chung KH, Deo M, Thompson RC, Turner DL (2008). MicroRNA miR-124 regulates neurite outgrowth during neuronal differentiation. Exp Cell Res 314: 2618-2633.

Supplementary Information accompanies the paper on the Neuropsychopharmacology website (http://www.nature.com/npp) 